\title{
ICE-FABRIC STUDY OF THE MAWSON REGION, EAST ANTARGTICA
}

\author{
By K. KIZAKI* \\ (Antarctic Division, Department of External Affairs, Melbourne, Victoria, Australia)
}

\begin{abstract}
Attempts are made to test the relation predicted by Brace ( 1960 ) between strain-rates and the ice-fabric patterns obtained at Mawson station, east Antarctica. These orientation fabrics not only are hardly related to the prediction by Brace (1960) or Kamb (1959) but also change easily within a strain grid with $100 \mathrm{~m}$ diagonals.

Stable patterns of two- and three-maximum fabrics are confirmed. The latter is common and stable in the coarse ice at the surface of the ice sheet. It is apparent that the fabric patterns are generally related to the grain-size. The single-maximum fabric always occurs in fine-grained ice, then more maxima are formed in the course of grain growth.

It appears that syntectonic-secondary recrystallization is effective in producing the orientation fabrics with two, three and multiple maxima. Also, the maxima always shift away from the pole of foliation as grain-size increases and there are several stable positions of maximum such as $0^{\circ}, 17^{\circ}, 23^{\circ}$ and $30^{\circ}$. It is expected that further stable angles would occur with coarser crystals as found in temperate glaciers.

RÉsumé. Fabrique de glace de la région de Mawson, Antarctique orientale. Des essais ont été réalisés pour tester la relation prévue par Brace (1960) entre la vitesse de déformation et les figures de fabrique de glace obtenues à la station Mawson, Antarctique orientale. Ces fabriques d'orientation ne sont pas seulement fortement liées aux prédictions de Brace (1960) et de Kamb (1959) mais changeent aussi dans une grille de déformation avec des diagonales de $100 \mathrm{~m}$.

Des figures stables à deux ou trois maximum de fabrique ont été confirmées. Les dernières sont communes et stables dans la glace à gros grains à la surface de l'indlandsis. Il apparaît que les figures de fabrique sont en général en relation avec la grandeur des grains. La fabrique à un seul maximum de figure existe toujours dans la glace à grains fins, puis plus de maximum se forment au cours de la croissance des grains.

Il apparaît que la recristallisation secondaire syntectonic est effective en produisant les fabriques d'orientation avec deux, trois ou plus de maximum. De même, le maximum glisse toujours loin du pôle de foliation avec l'augmentation des dimensions des grains, et il y a plusieurs positions stables du maximum comme à $0^{\circ}, 17^{\circ}, 23^{\circ}$ et $30^{\circ}$. On pense que d'autres angles stables pourraient apparaître avec des cristaux plus gros comme il s'en trouve dans les glaciers tempérés.
\end{abstract}

Zusammenfassung. Eisgefügeuntersuchungen in der Mawson-Region, Ost-Antarktika. Es wurde versucht, die von Brace (1960) voraugesagte Beziehung zwischen Deformationsgeschwindigkeiten und den Mustern des Eisgefüges an Proben zu prüfen, die an der Mawson Station, Ost-Antarktika, gewonnen worden waren. Diese orientierten Gefüge zeigen nicht nur so gut wie keine Übereinstimmung mit der Vorhersage von Brace ( I 960 ) oder Kamb (1959), sondern sie verändern sich auch leicht innerhalb eines Spannungsgitters mit $100 \mathrm{~m}$ Diagonalenlänge.

Stabile Gefügemuster mit zwei- und dreifachen Extremwerten wurden festgestellt. Die letzteren sind im grobkörnigen Eis an der Oberfläche des Inlandeises weitverbreitet und stabil. Offensichtlich sind die Gefügemuster allgemein von der Korngrösse abhängig. Gefüge mit einem Extremum treten immer in feinkörnigem Eis auf, mehr Extremwerte bilden sich dann mit dem Kornwachstum.

Es scheint, dass sekundäre syntektonische Rekristallisation eine Rolle bei der Bildung von orientierten Gefügen mit zwei-, drei- oder mehrfachen Extremwerten spielt. Ebenso entfernen sich mit zunehmender Korngrösse die Maxima immer vom Pol der Bänderung; dabei gibt es einige stabile Positionen der Maximalwerte, etwa $0^{\circ}, 17^{\circ}, 23^{\circ}$ und $30^{\circ}$. In gröberen Kristallen, wie sie in temperierten Gletschern vorkommen, ist das Auftreten weiterer stabiler Winkel zu erwarten.

\section{INTRODUCTION}

Following the original studies by Bader (I95I) and Rigsby (I95I) on the fabric of glacier ice, which presented a complicated problem on the orientation mechanism of the ice crystal and the patterns of its fabric, several studies have been carried out to try to explain the problem both from the experimental and the theoretical point of view (Shumskiy, r958; Steinemann, I958, p. 46-50; Kamb, I959; Brace, I96o; Rigsby, I96o). In addition to these, structural glaciological studies (Meier, 1960; Taylor, 1963; Reid, I964) provided more precise figures on the relationship of glacier tectonics to the fabrics. All this, however, did not seem to explain the problem satisfactorily.

* Present address: Department of Geology and Mineralogy, Hokkaido University, Sapporo, Japan. 
The present study in the vicinity of Mawson station, east Antarctica, was originally undertaken with the object of attempting to examine the relationship between the strain and fabric pattern. For this purpose, three strain grids were set up on the ice surface and two or more specimens were collected from each grid to reveal the fabric-orientation pattern associated with each of the measured strain-rates. Furthermore, a comprehensive fabric investigation on the ice sheet was carried out and about 35 specimens were collected, not only from the surface of the ice sheet, but also from the bottom of the ice cliffs.

The observations and measurements given in this paper were made during 1966 as a part of the glaciological programme of the Australian National Antarctic Research Expeditions (A.N.A.R.E.) at Mawson station, which is located at lat. $67^{\circ} 36^{\prime}$ S., long. $62^{\circ} 52^{\prime}$ E. near the head of Horseshoe Harbour in Mac.Robertson Land, Antarctica.

\section{Physical Setting}

The ice sheet between the coast and the Framnes Mountains has an extensive area of bare ice up to $15 \mathrm{~km}$ and more from the coast, and here it flows with varying velocity. One of the outlet streams from the ice sheet and the surrounding area west of Mawson station were selected for the present investigation (Fig. I).

The area between Mawson and Marble Rock is rich in its variety of morphological and structural features. Immediately west of Mawson, a broad shallow gully forms a small accumulation basin, which is covered with a thin snow drift less than $5^{\circ} \mathrm{cm}$ deep in winter but has bare ice exposed in summer. The bare ice, however, was found to be newly formed ice recrystallized from snow in situ. To the west of the gully, a higher plateau of the ice sheet with indistinct vertical foliation protrudes northwards ending in ice cliffs $30 \mathrm{~m}$ high.

Farther west, a hill with severe crevassing on the crest suggests a bedrock protuberance beneath the ice. Marble Rock, at the extreme west, obstructs the outward flow of the ice stream so that the ice thrusts up towards the rock to form peculiar structures such as an overturned fold and a shear-moraine belt.

\section{Temperature and Ablation}

Monthly mean temperatures at Mawson in 1966 are given in Table I. The temperature always rises above freezing point in the daytime during December and January, and it has reached a maximum of $5.9^{\circ} \mathrm{C}$ in December. Therefore, the condition of the surface ice of the region cannot represent real polar ice, since it is similar to temperate ice for the short summer period. The ablation near Mawson is comparatively high: approximately $50 \mathrm{~cm}$ year-1 (Budd, 1967).

Table I. Monthly Mean Temperature $\left({ }^{\circ} \mathrm{C}\right)$

$\begin{array}{cccccccccccc}\text { Jan. } & \text { Feb. } & \text { March } & \text { April } & \text { May } & \text { June } & \text { July } & \text { Aug. } & \text { Sept. } & \text { Oct. } & \text { Nov. } & \text { Dec. } \\ -0.8 & -3.5 & -8.0 & -18.2 & -13.0 & -18.5 & -14.6 & -22.4 & -15.4 & -14.1 & -5.7 & -0.4\end{array}$

\section{Structural Features}

The structural features of a glacier are generally characterized by planar structures such as foliation, clear bands, cleavages and crevasses, all of which are developed in this region.

Foliation. The foliation, as a rule, is defined by alternating layers of bubbly and bubblefree ice of variable thickness. However, the foliation of the ice stream in this region can be recognized clearly only from a distance or from the air and not in the ice specimen, because there is not much differentiation of bubbles in the layers which are consistently vertical throughout the ice sheet between Mawson and the Framnes Mountains. The partial development of a pronounced banded structure of clear ice and bubble-rich layers is observed as 


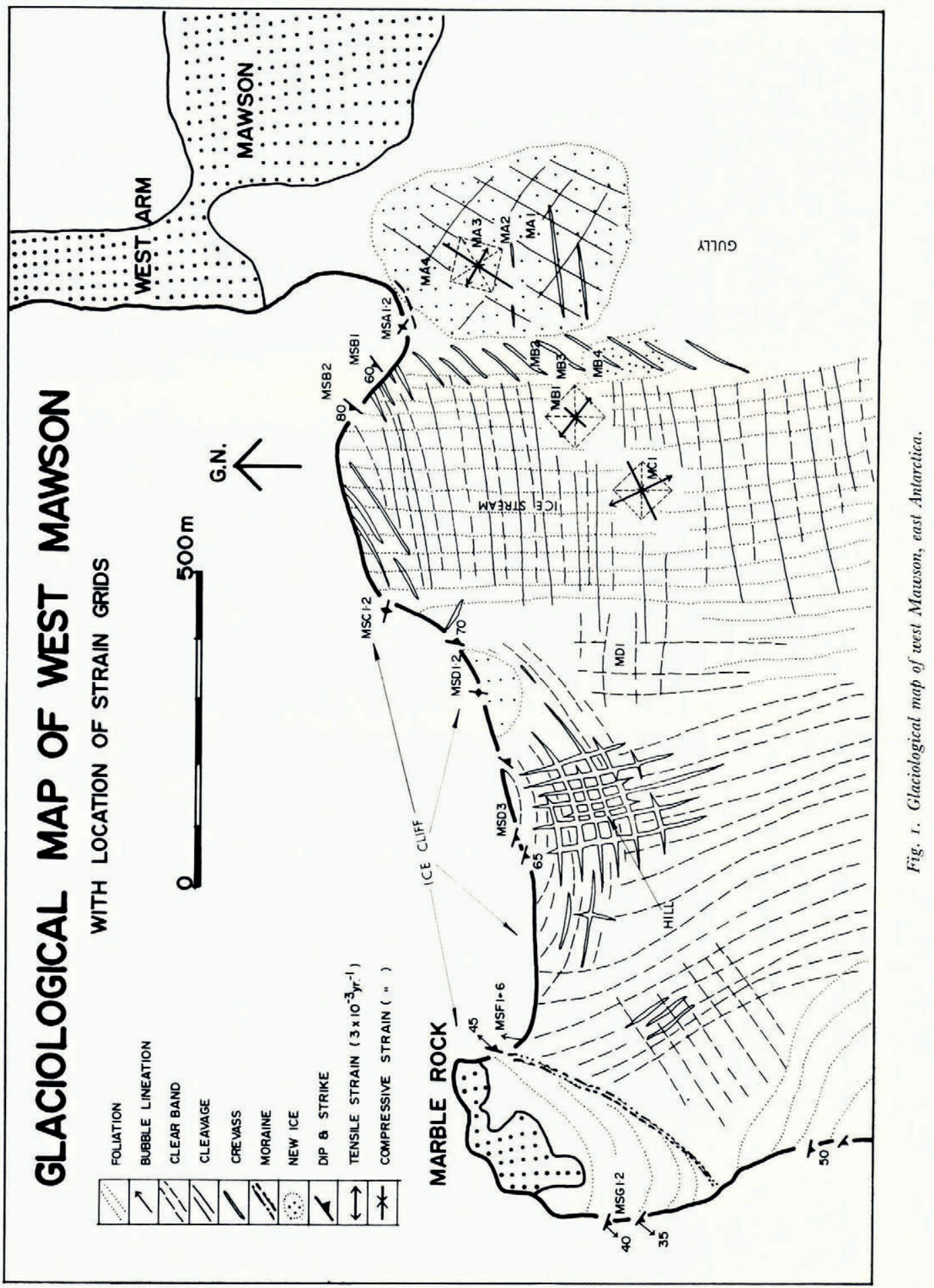


alternating layers varying from 0.5 to $5 \mathrm{~cm}$ in thickness in the Marble Rock area. This could have been caused by the intense shearing resulting from the upthrusting movement towards Marble Rock.

Clear bands. A conspicuous structural feature in most glaciers is the clear band, which is defined as an almost bubble-free band of transparent ice set in predominantly bubbly glacier ice. In this region, clear bands can be seen everywhere on the surface of the ice sheet. Most of these bands include a layer of bubbles in the middle part parallel to the wall of the band, and this always occurs parallel to cleavages or crevasses, suggesting an origin similar to that of the cleavages and crevasses.

Cleavage. A planar structure indicated by a closed crack is described here as a cleavage. The cleavages of the eastern gully show a pattern of tension but those of the plateau indicate shear.

Bubble lineation. The only linear element in glacier structures is the preferred orientation of bubbles. They are always vertical in the new ice at the gully, but they can indicate the flow direction where the differential movement is intense such as in the thrust structure of Marble Rock.

\section{Surface Velocity and Strain-Rate}

Grids for measuring strain-rates on the ice surface were set up at three points designated as $\mathrm{A}$ at the centre of the gully, B and C on the ice stream (Fig. I). Each grid had roo $\mathrm{m}$ diagonals and was measured twice during the year (see Table II). A third measurement at the end of the year was unsuccessful because the ice melted and some of the stakes floated away. A theodolite station was fixed on the rock of the hill for measurement of the velocity of the ice sheet, in the same way as the measurements carried out by M. Mellor in 1957 (Mellor, I959) (see Table II).

\begin{tabular}{|c|c|c|c|}
\hline Grid & $A$ & $B$ & $C$ \\
\hline $\begin{array}{l}\text { Distance from theodolite point } \\
(\mathrm{m})\end{array}$ & 200 & 500 & $659 \cdot 5$ \\
\hline \multicolumn{4}{|l|}{ Displacement (m) } \\
\hline $\begin{array}{l}7 \text { April-21 October I } 966 \\
\text { 21 October 1966-17 January }\end{array}$ & o & $5 \cdot 9$ & 6.4 \\
\hline I967 & 0.02 & 3.1 & 2.7 \\
\hline Total ( 285 days) & 0.02 & 9.0 & $9 \cdot 1$ \\
\hline Velocity (m/year) & 0.03 & 11.5 & 11.7 \\
\hline \multicolumn{4}{|c|}{ M. Mellor's Results (1957) } \\
\hline & Stake I & Stake 2 & Stake 4 \\
\hline \multicolumn{4}{|l|}{ Displacement (m) } \\
\hline Total (296 days) & o & 9.05 & $9 \cdot 8_{4}$ \\
\hline Velocity (m/year) & o & I 1.2 & 12.1 \\
\hline
\end{tabular}

The measurements and calculations of strain-rate followed the procedure outlined by Nye (1959).

The results of the measured and principal strain-rates are given in Table III, and the directions of the principal strain-rates at A, B and C are shown by the arrows plotted in Figure I. The general direction of the crevasses between the gully and the ice stream is parallel to the direction of the maximum compression axis. Nye (1959), Ward (1955), and $\mathrm{Wu}$ and Christensen (1964) have shown that crevasses in glaciers are the result of tensile stresses, and that they trend in a direction perpendicular to that of the maximum tensile stress. In the present case the agreement is considered satisfactory. 
Table III. Measured Strains and Calculated Principal Strain-Rates $\left(\times 10^{-3}\right.$ year $^{-1}$ )

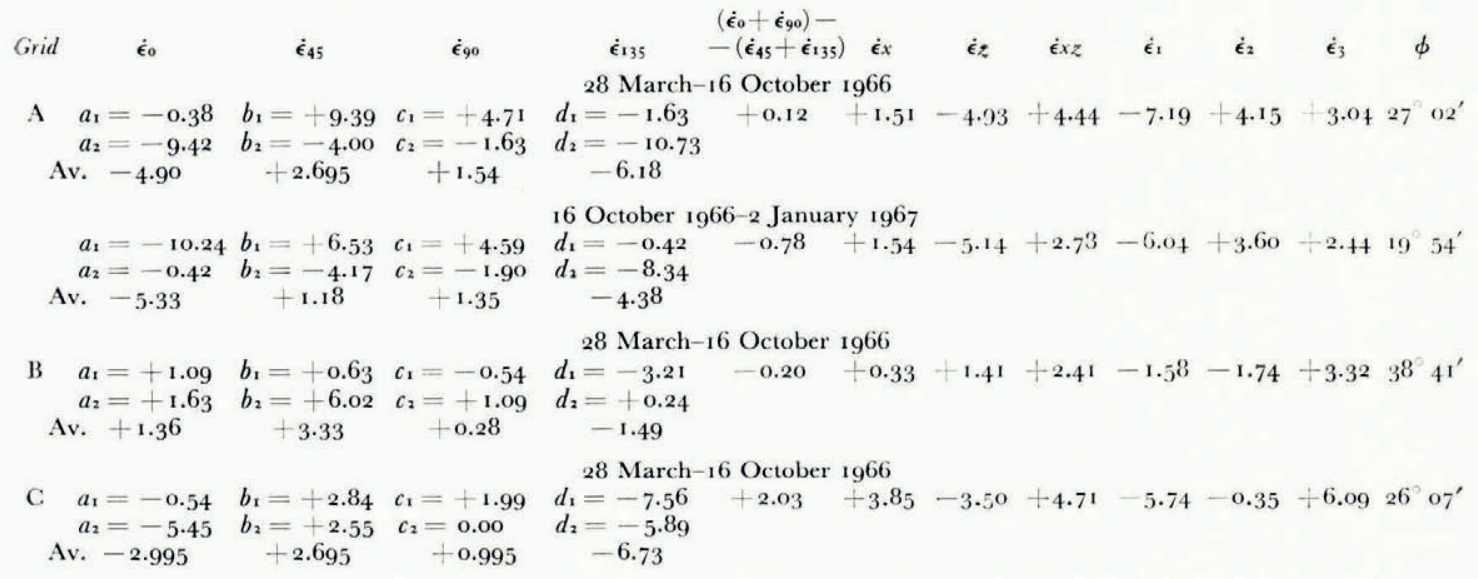

The $x$-axis is along one diagonal and is directed down the ice flow; the $z$-axis is along the other diagonal, and the $y$-axis is normal to the ice surface.

At grid A, the cleavages have two directions which seem to be parallel to those of the two principal axes, but the cleavage at grids B and $\mathrm{C}$ has only one direction, viz. approximately parallel to one of the maximum shear planes.

The foliation plane, which has been regarded sometimes as the plane parallel to a shear plane, is obviously parallel to one of the maximum shear directions at grid B, but the discrepancy between the direction of the foliation and that of maximum shear at grid $\mathrm{C}$ is almost $20^{\circ}$.

However, it seems reasonable that the foliation is the result of shearing movement during the flow of ice over a long distance, in spite of some local fluctuations of shear direction such as at grid $\mathrm{C}$.

\section{Fabric Analysis}

Ice specimens were cut from 18 localities, not only from the surface ice within and near each strain grid but also from the ice cliff at the coast (Fig. I).

Orientations of the $c$-axes of the ice were measured by the universal-stage technique described by Bader (I95I), Rigsby (I95I) and Langway (I958). The $c$-axis orientations were plotted on the lower hemisphere using a Schmidt equal-area projection, and they were contoured by conventional statistical methods (Fairbairn and Chayes, 1949; Langway, 1958). The measured $c$-axis inclinations were corrected for refractive index by Snell's law before being plotted. Most of the diagrams are presented in the horizontal projection plane but some of them are vertical sections. The projections are indicated by a local coordinate system, consisting of orthogonal axes labelled n-s, w-e and up-dn. Structural-control elements, such as foliation, axial plane, clear bands, cleavage and bubble lineation, are shown in these diagrams to indicate the relationship between the orientation of $c$-axes and their controlling elements.

The fabric data obtained from the Mawson region are summarized in Table IV.

\section{Fabrics of new ice}

The gully in which strain grid A was located is one of the small accumulation basins where snow patches occurred on the bare ice of the plateau. It is characterized by newly formed ice which is generally difficult to distinguish from the ordinary glacier ice without examining a 
Table IV. Fabric Data from the Mawson Region

\begin{tabular}{|c|c|c|c|c|c|c|}
\hline $\begin{array}{c}\text { Locality } \\
\text { (cf. Fig. I) }\end{array}$ & $\begin{array}{l}\text { Number of } \\
\text { specimen }\end{array}$ & Ice type & $\begin{array}{c}\text { Number of } \\
\text { axes }\end{array}$ & Fabric type & $\begin{array}{l}\text { Number } / \mathrm{cm}^{2} \\
\text { (grain-size })\end{array}$ & \\
\hline MA & I & $\begin{array}{l}\text { Polygonal. } \\
\text { New ice }\end{array}$ & 210 & I max. with girdle & 2.3 & \\
\hline MA & 2 & $\begin{array}{l}\text { Polygonal. } \\
\text { New ice }\end{array}$ & 200 & 2 max. with girdle & I.7 & \\
\hline MA & 3 & $\begin{array}{l}\text { Polygonal. } \\
\text { New ice }\end{array}$ & 230 & $\begin{array}{l}4 \text { max. (not diamond) } \\
\text { with girdle }\end{array}$ & 1.2 & \\
\hline MA & 4 & $\begin{array}{l}\text { Equigranular. } \\
\text { New ice }\end{array}$ & 172 & $\begin{array}{l}4 \text { max. (not diamond) } \\
\text { with small girdle }\end{array}$ & I.5 & \\
\hline MSA & Ia & Fine & I30 & I max. $\left(16^{\circ}\right)$; sub-max. & I 3.5 & Bubble part \\
\hline MSA & Ib & Fine & ${ }^{1} 5^{\circ}$ & $\begin{array}{l}\text { I } \max .\left(17^{\circ}\right) \text { with } \\
\text { girdle }\end{array}$ & $9 \cdot 3$ & Clear part \\
\hline MSA & 2 & Fine & 232 & $1 \max .\left(13^{\circ}\right)$ & 5.8 & 3 max. and \\
\hline $\mathrm{MB}$ & Ia & Coarse & 173 & 3 max. & 0.7 & Clear \\
\hline MB & Ib & Coarse & 110 & $\begin{array}{l}3 \text { max. with small } \\
\text { girdle }\end{array}$ & 0.9 & Clear \\
\hline MB & 2 & Medium & ${ }^{1} 4^{2}$ & I max. with girdle & 1.2 & $\begin{array}{l}\text { A little elongated. } \\
\text { Shear zone }\end{array}$ \\
\hline $\begin{array}{l}\text { MB } \\
\text { MB }\end{array}$ & $\begin{array}{l}3 \\
4^{\mathrm{a}}\end{array}$ & $\begin{array}{l}\text { Coarse } \\
\text { Medium }\end{array}$ & $\begin{array}{l}125 \\
120\end{array}$ & $\begin{array}{l}2 \text { max. with sub-max. } \\
\text { I max. with girdle }\end{array}$ & $\begin{array}{l}0.5 \\
\text { I.1 }\end{array}$ & $\begin{array}{l}\text { Coarse mixture } \\
\text { with small. } \\
\text { Heterogeneous }\end{array}$ \\
\hline $\mathrm{MB}$ & $4^{b}$ & Medium & I5O & 2 max. with girdle & I. 4 & $\begin{array}{l}\text { Heterogeneous } \\
\text { Heterogeneous }\end{array}$ \\
\hline MSB & I & Fine & 140 & I $\max$ & 12.5 & Clear, shear zone \\
\hline MSB & 2 & Medium & I Io & $2 \max$ & 4.0 & Clear \\
\hline MC & Ia & Coarse & 105 & $3 \max$. & 0.4 & Clear \\
\hline $\mathrm{MC}$ & Ib & Coarse & 195 & 3 max. & 0.4 & Clear \\
\hline MSC & I & Fine & 160 & $2 \max$. & 6.0 & $30 \mathrm{~m}$ from surface \\
\hline MSC & 2 & Coarse & 62 & 4 max. incomplete & 0.5 & $20 \mathrm{~m}$ from surface \\
\hline MD & I & Coarse & 154 & Multiple max. & 0.7 & Superimposed? \\
\hline MSD & I & Coarse & 137 & I $\max$. & 0.6 & \\
\hline MSD & 3 & Coarse & 145 & 4 diamond max. & 0.6 & Clear \\
\hline MSG & I & Medium & $13^{2}$ & $3 \max$ & I. 2 & $\begin{array}{l}\text { Incomplete } 4 \\
\text { max. (diamond) }\end{array}$ \\
\hline MSG & $2 \mathrm{a}$ & Coarse & 100 & 4 max. & 0.7 & $\begin{array}{l}\text { Clear. Coarse } \\
\text { part }\end{array}$ \\
\hline MSG & $2 \mathrm{~b}$ & Medium & 160 & $3 \max$. & І. 6 & $\begin{array}{l}\text { Clear. Bubble } \\
\text { part }\end{array}$ \\
\hline $\begin{array}{l}\text { MSF } \\
\text { MSF }\end{array}$ & $\begin{array}{l}1 \\
2\end{array}$ & $\begin{array}{l}\text { Medium } \\
\text { Fine }\end{array}$ & $\begin{array}{l}140 \\
220\end{array}$ & $\begin{array}{l}3 \text { max. } \\
\text { I max. }\end{array}$ & $\begin{array}{r}1.2 \\
13.0\end{array}$ & $\begin{array}{l}\text { Elongate } \\
\text { Clear Elongate }\end{array}$ \\
\hline MSF & 3 & Fine & 160 & I max. with girdle & $\begin{array}{l}13.0 \\
15.0\end{array}$ & $\begin{array}{l}\text { Clear. Elongate } \\
\text { Clear }\end{array}$ \\
\hline MSF & 4 & Fine & 180 & I $\max$. & 9.0 & Clear \\
\hline MSF & 5 & Medium & 170 & $\begin{array}{l}\text { I max. with small } \\
\text { girdle }\end{array}$ & $3 \cdot 3$ & Clear \\
\hline MSF & 6 & Fine & $\begin{array}{l}210 \\
100\end{array}$ & $3 \max$. & $\begin{array}{l}6.3 \\
0.7\end{array}$ & Clear \\
\hline $\begin{array}{l}\text { RM } \\
\text { FG* }\end{array}$ & $\begin{array}{l}\text { I } \\
\text { Ia }\end{array}$ & $\begin{array}{l}\text { Coarse } \\
\text { Medium }\end{array}$ & $\begin{array}{l}100 \\
140\end{array}$ & $\begin{array}{l}3 \text { max. } \\
3 \text { max. }\end{array}$ & $\begin{array}{l}0.7 \\
1.2\end{array}$ & $\begin{array}{l}\text { Clear } \\
\text { Clear } 5 \mathrm{~m} \text { from }\end{array}$ \\
\hline FG* & Ia & Medium & & $3 \max$. & 1.2 & $\begin{array}{l}\text { Clear, } 5 \mathrm{~m} \text { from } \\
\text { surface }\end{array}$ \\
\hline $\begin{array}{l}\mathrm{FG}^{*} \\
\mathrm{FG}^{*}\end{array}$ & $\begin{array}{l}1 \mathrm{~b} \\
2\end{array}$ & $\begin{array}{l}\text { Medium } \\
\text { Fine }\end{array}$ & $\begin{array}{l}220 \\
260\end{array}$ & $\begin{array}{l}2 \max . \\
2 \max .\end{array}$ & $\begin{array}{l}2.0 \\
5.5\end{array}$ & $\begin{array}{l}\text { Diverging figure } \\
\text { Superimposed. }\end{array}$ \\
\hline $\mathrm{FG}^{*}$ & 3 & Coarse & 170 & $3 \max$. & 0.7 & \\
\hline & $J$ & & o & & & Clear, surface \\
\hline
\end{tabular}

* FG fabrics were obtained from the tongue of Forbes Glacier, $20 \mathrm{~km}$ west of Mawson.

thin section of the ice between polaroids. This basin has a bubbly ice cover several metres thick. This bubbly ice is sometimes intercalated horizontally with solid granular snow layers unconformably overlying older glacier ice, as seen in the MSD basin (Fig. I).

Four specimens were collected within $50 \mathrm{~m}$ of and in the strain grid $\mathrm{A}$, and designated as MAI to $\mathrm{MA}_{4}$ from south to north. The ice has horizontal bubble layers, although these are faint and sometimes obscured, and the bubbles are elongated vertically. The ice crystals are 
fine to medium ( 0.2 to $2.5 \mathrm{~cm}$ in diameter) in size and the characteristic polygonal appearance of the hexagonal crystals is a clear indication of the ice having been formed from snow recently.

Specimen MA4, collected at the northernmost location in the area, shows equigranular and anhedral crystal shapes but some relics of the polygonal structure persist. Strain shadows within several of the grains also indicate that the ice is at a more advanced stage of the deformation process than the newly formed ice.

We now examine Figure $2 \mathrm{a}-\mathrm{d}$ and their fabric-orientation patterns. $X, Y$ and $Z$ are the principal stress axes in which the maximum compression axis is designated by $X$, and the maximum tensile axis, $Z$, as obtained from the measurements of strain grid A.

MAI (Fig. 2a) shows a vague girdle parallel to the $Z \gamma$ plane. An incomplete girdle along the $X Z$ plane with some weak maxima around the $Z$-axis appears in MA2 (Fig. 2b) and MA3 (Fig. 2c). In $\mathrm{MA}_{4}$ (Fig. 2d) the pattern is completely different from the others, having a small girdle around $X$ with some weak maxima, whilst the $c$-axes distributed about $Z$ in MA2 and $\mathrm{MA}_{3}$ are absent.

On the basis of the assumption that the strain-rates are uniform over the area of the grid where these specimens were collected, it is noticeable that the orientation pattern of the icecrystal axes have changed considerably from MAI to MA4, i.e. from a girdle parallel to the $Z \Upsilon$ plane to a small girdle about $X$ with an $X Y$ girdle.

The stress distribution of the grid A can be adapted to Brace's (196o, p. 19) case I, in which a small girdle would be expected from theory to form around the maximum compression stress axis $X$. Such a pattern is found in $\mathrm{MA}_{4}$, from outside the grid where the deformation texture is more dominant than in the other sections.

Could the other three patterns be recrystallization fabrics under the same stress-strain circumstances? These fabrics do not fit the patterns of recrystallization fabric predicted by Kamb (1959, p. r69), but systematic grain growth is evident as follows:

$\begin{array}{ccccc} & \text { MAI } & \text { MA2 } & \text { MA3 } & \text { MA4 } \\ \begin{array}{c}\text { Grain-size } \\ \text { grain numbers } / \mathrm{cm}^{2} \text { ) }\end{array} & 2.3 & \text { I.7 } & \text { I.2, o.8 } & \text { I.5 } \\ \begin{array}{c}\text { Texture } \\ \text { polygonal }\end{array} & \text { polygonal } & \text { polygonal } & \begin{array}{c}\text { equigranular; } \\ \text { strain shadow }\end{array}\end{array}$

The grains of ice grow gradually, retaining a polygonal structure, and their size decreases again in the deformed texture of MA4. Therefore, recrystallization growth is the most likely cause of change in the pattern.

Near grid B two specimens were collected which were found to be new ice. Although the fabrics of their $c$-axis orientations $\left(\mathrm{MB}_{4} \mathrm{a}\right.$ and $\mathrm{MB}_{4} \mathrm{~b}$; Fig. $2 \mathrm{e}$ and $\mathrm{f}$ ) are identical to those of $\mathrm{MA}_{4}$, their strain-rates are different. They have anhedral small crystals as well as porphyritic coarse crystals up to $3 \mathrm{~cm}$ in diameter, particularly in the specimen of $\mathrm{MB}_{4} \mathrm{a}$. In general, the bubbles are arranged vertically though some of them lie parallel to the flow direction in $\mathrm{MB}_{4}$ a.

It is interesting that the fabric of $\mathrm{MB}_{4} \mathrm{~b}$, which is equigranular and smaller in grain-size with less bubble lineation than $\mathrm{MB}_{4}$ a, tends to have a small girdle around the maximum compression axis $X$ and also an $X Y$ girdle just the same as in MA4. In contrast to this, the fabric of $\mathrm{MB}_{4} \mathrm{a}$, which is porphyritic in texture, coarser in grain-size and has a marked clearbubble lineation parallel to the flow, has an incomplete small girdle not around the $X$-axis but around the pole of assumed foliation, and it still shows the $X Y$ girdle. This could be a transitional phase to a small girdle around the pole of the foliation plane from one around the maximum compression axis $X$, arising in the course of grain-growth crystallization and from the incipient foliation at the shear zone.

It is now clear that grain growth has an important role in producing the fabric pattern. 


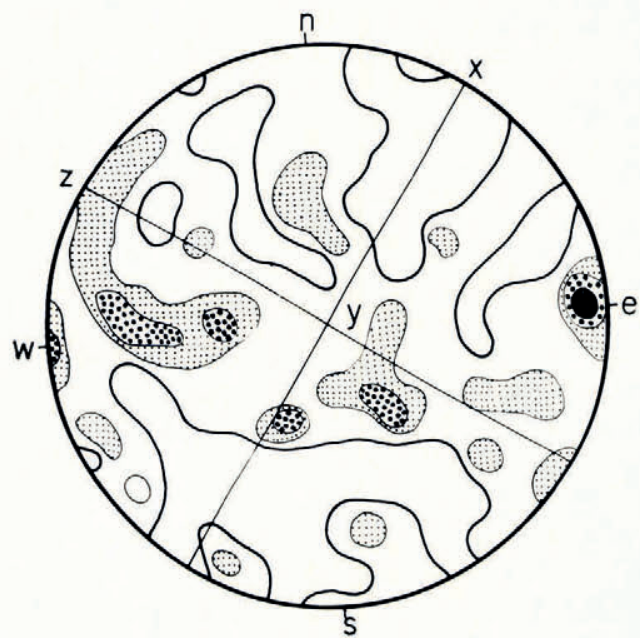

(a)

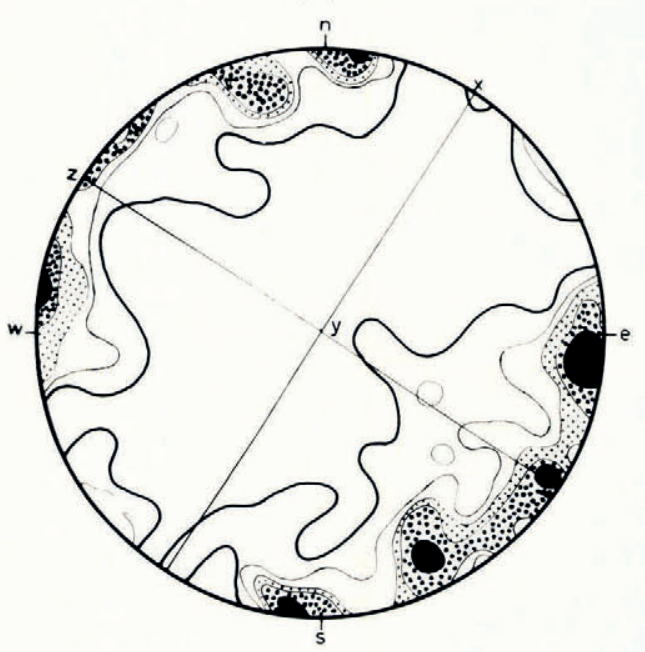

(c)

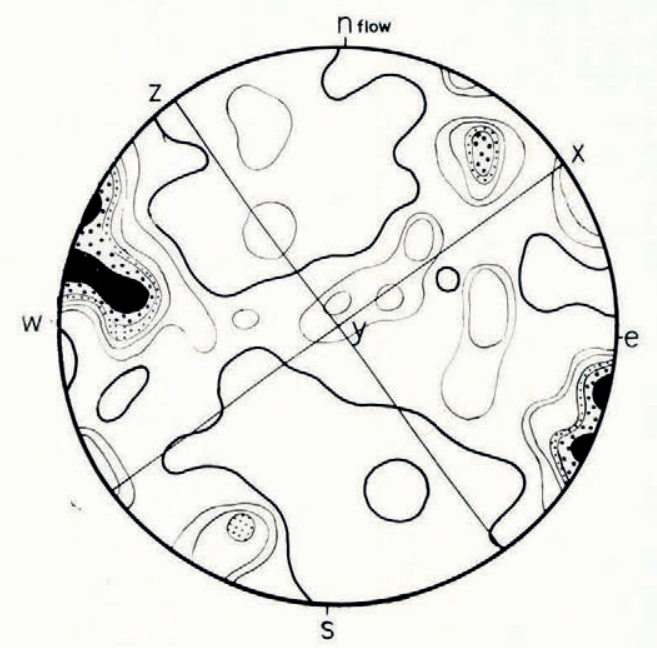

(e)

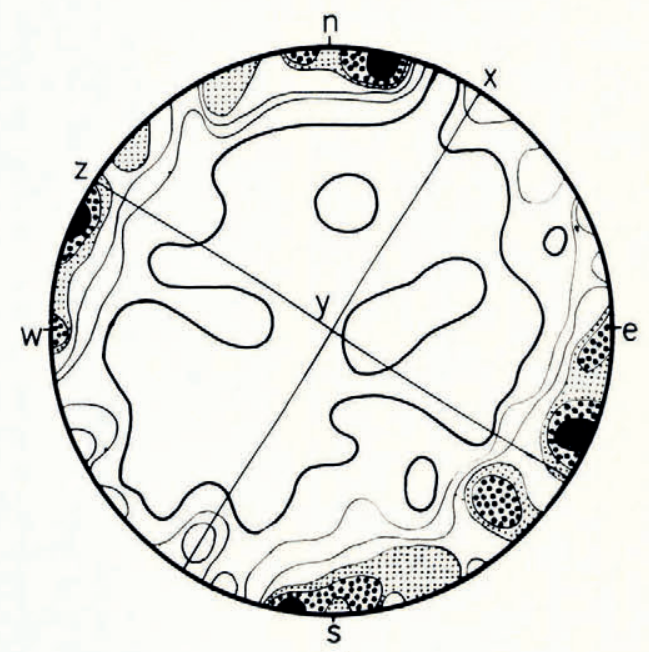

(b)

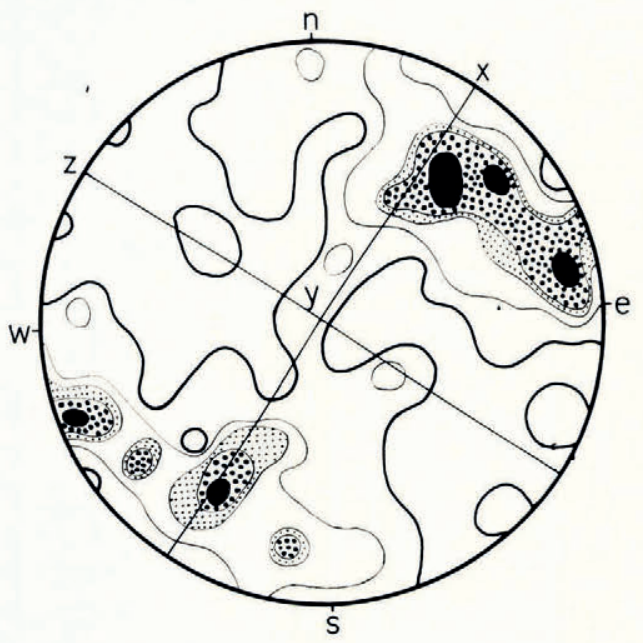

(d)

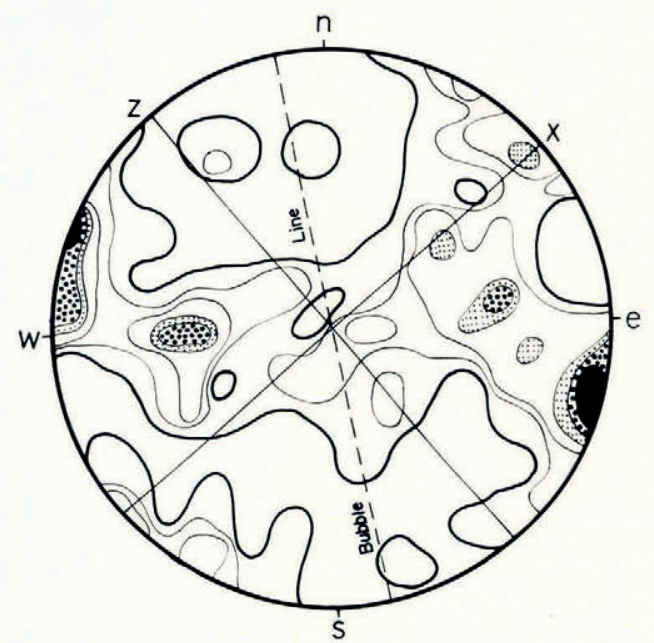

(f) 


\section{Fabrics of coarse ice}

The surface of the plateau ice and outlet ice stream below the firn line, which lies about $20 \mathrm{~km}$ south of Mawson in the summer, is composed mainly of coarse bubbly ice. No fine ice bands, such as occur in temperate glaciers, were found anywhere in this region. It was revealed by continuous sections that crystals, generally i to $5 \mathrm{~cm}$ in diameter, sometimes grow up to $10 \mathrm{~cm}$ and even longer vertically. An anhedral, irregular and interlocking texture is common throughout. Bubbles are round and ovoid, I to $2 \mathrm{~mm}$ long, and have bubble pressures of $\mathrm{I}$ to $\mathrm{I} .5$ atmospheres. * These bubbles tend to cluster into indistinct layers, giving rise to indistinct foliated structures, but the differentiation is not sufficient to make the structure discernible in a specimen, though the foliations as a flow structure can be clearly observed from a distance.

The coarse ice has a fabric containing several $c$-axis maxima. It is found that the threemaxima fabric is common at the surface of the ice sheet, although four-maxima fabrics are obtained from the ice cliffs at the edge of the ice sheet.

A typical three-maxima fabric is that from the strain grid B (Fig. $3 \mathrm{a}$ and b). The maxima have a density of more than $9 \%$ per $\mathrm{I} \%$ area and are connected by a small girdle, the centre of which is situated at the pole of the foliation plane. The same three-maxima patterns are found at strain grid C (Fig. 3c) and also from the surface of the plateau io km south of Mawson (RMI, Fig. 3d).

The strain-rates at grids B and C are listed in Table III. The centre of a small girdle is generally located near the pole of foliation, as in the case of all of the typical four-maxima fabrics which have been obtained so far. They may be recrystallization fabrics, since they have coarser crystals ranging from 0.4 to 0.9 grains per $\mathrm{cm}^{2}$ on the average. Some changes in pattern can be recognized in these diagrams from MCI and $\mathrm{MB}_{\mathrm{I}}$ to $\mathrm{MB}_{3}$ (Fig. $3 \mathrm{e}$ ) and then a complete change to a single-maximum fabric $\left(\mathrm{MB}_{2}\right.$, Fig. $\left.3 \mathrm{f}\right)$ at the high shear zone located between the ice stream and the stagnant gully. The three maxima in MGI seem to be related to the foliation, though it is not as distinct as in $\mathrm{MBI}$, and a small girdle around $X$ is indicated. This appearance of a small girdle does not confirm the prediction by Brace (1950, p. I9) for the strain-rate distribution appropriate to case I in his treatment. The fabric of MBI has three maxima with a small girdle, the centre of which has moved to coincide with the pole of foliation. This pattern seems to be a recrystallization fabric as in the case of the four-maxima fabrics. Towards the shear zone at $\mathrm{MB}_{3}$ there appears an incomplete girdle with two dense maxima, and then the fabric completely changes to a single-maximum one with a great circle girdle at $\mathrm{MB}_{2}$ in the shear zone.

The change in these fabrics could depend upon the increasing shear stress from MC to the shear zone via MB from west to east.

Only one four-maxima fabric was obtained, viz. the one from $\mathrm{MSD}_{3}$ in the middle of the ice cliff. This fabric presents a more complex situation because of the disturbance to the ice stream caused by the protuberance of the sub-ice morphology.

The ice exhibits a linear structure of elongated bubbles in a north-south direction but no planar structure. A thin clear band containing fine bubbles folds monoclinally towards the west with an axis of $340^{\circ}$ (Fig. $4 \mathrm{a}$ and b). The fabric is undoubtedly superimposed by a later

* Bubble pressures were measured by the method of Scholander and Nutt ( 1960$)$.

\section{Fig. 2.}

a. 210 crystals of new ice $\left(M A_{I}\right)$, at grid $A$. Contours $I-2-3-4<\%$; maximum $4 \%$ per $I \%$ area. $X$, direction of the maximum compressive axis; $Z$, direction of the maximum tensile axis.

b. 200 crystals of new ice $(M A 2)$ at grid A. Contours $1-2-3-4-5-6<\% ;$ maximum $7 \%$ per $1 \%$ area.

c. 230 crystals of new ice $\left(M A_{3}\right)$ at grid $A$. Contours $I-2-3-4-5<\% ;$ maximum $6 \%$ per $1 \%$ area.

d. 172 crystals of new ice $(M A 4)$ at grid $A$. Contours $I-2-3-4-5<\% ;$ maximum $6 \%$ per $1 \%$ area.

e. $\quad{ }_{15}$ o crystals of new ice $(M B 4 b)$ near grid $B$. Contours $1-2-3-4-5-6<\%$; maximum $7 \%$ per $1 \%$ area.

$f$. I2o crystals of new ice $(M B 4 a)$ near grid $B$. Contours $I-2-3-4-5-6<\%$; maximum $8 \%$ per $I \%$ area. 


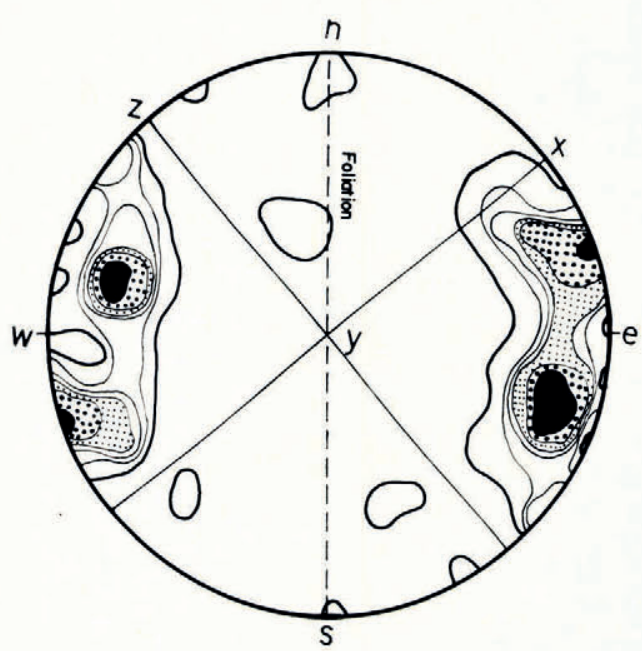

(a)

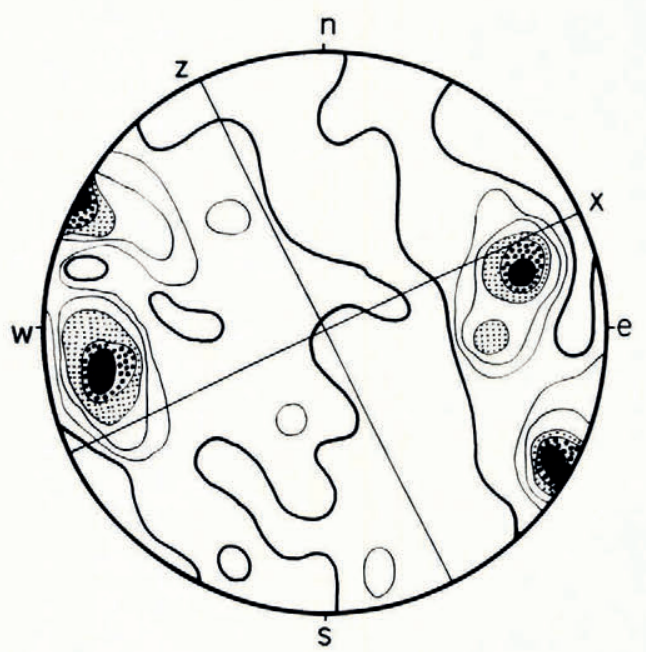

(c)

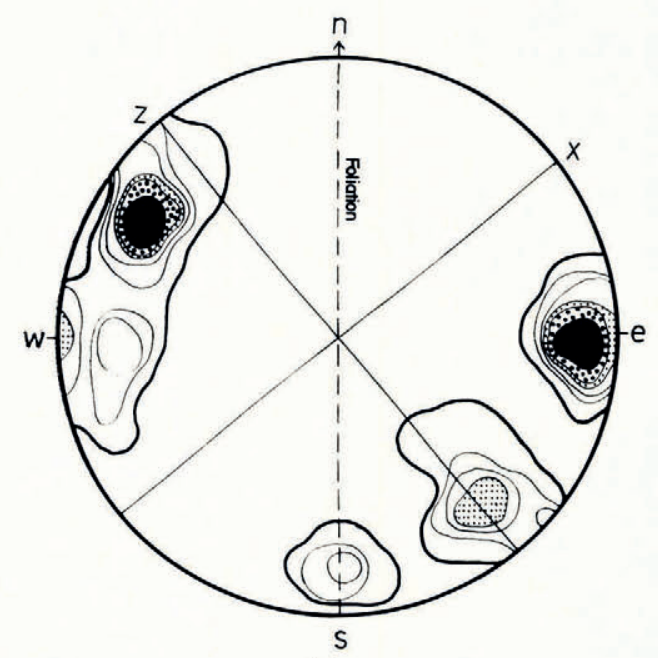

(e)
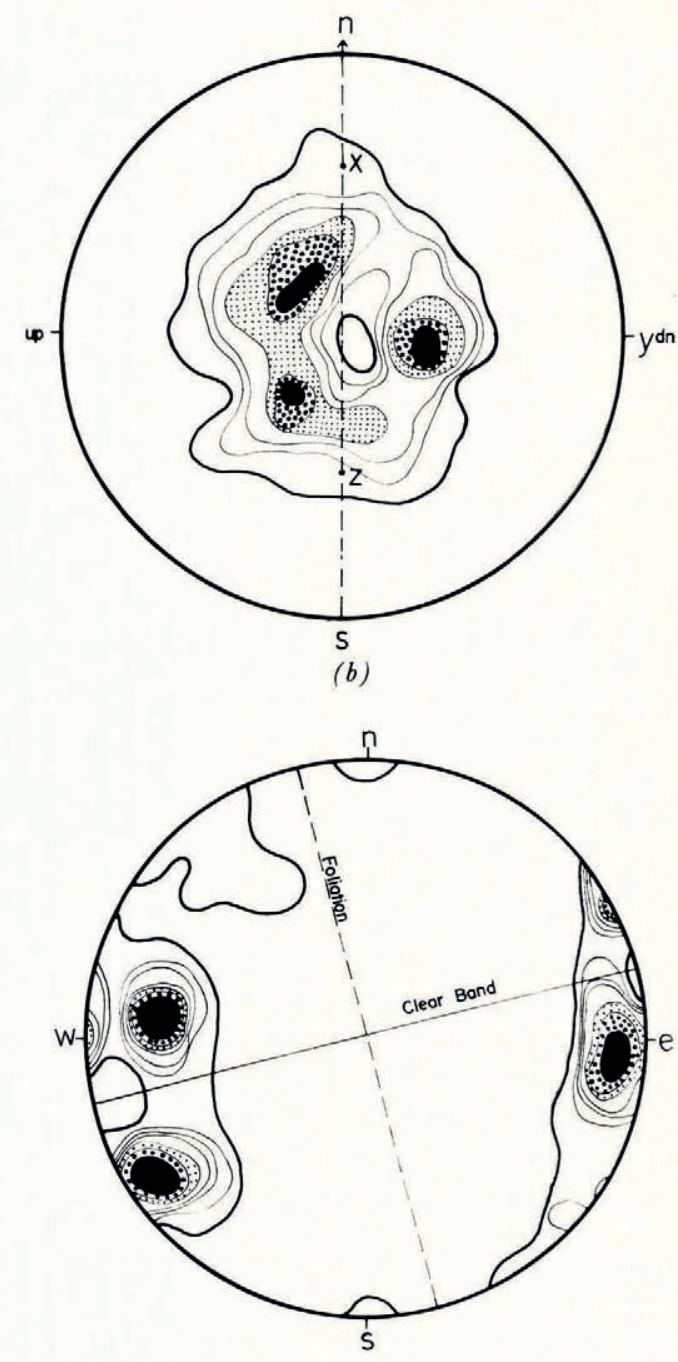

(d)

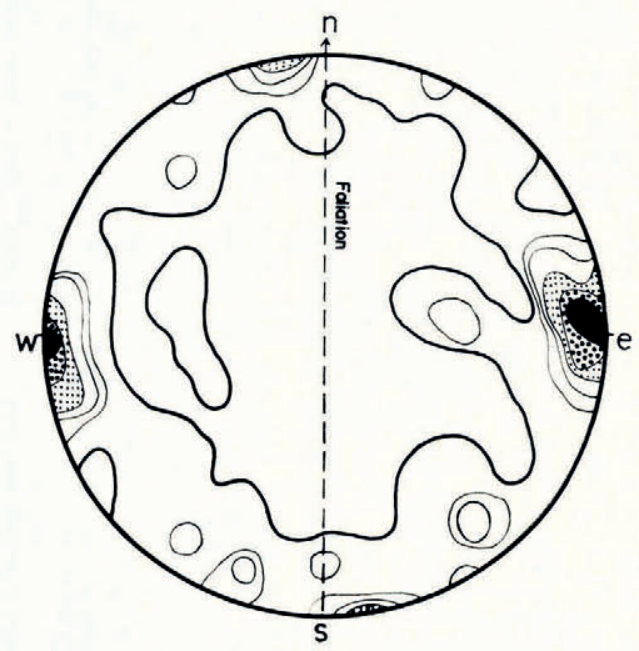

(f) 
deformation which is indicated by the folded clear band with an axis oblique to the flow line. The long axis of the diamond pattern in Figure $4 \mathrm{~b}$ is sub-parallel to the fold axis, which may represent the tensile axis, but the centre of the pattern does not coincide with the pole of any actual planar structure such as the axial plane of the fold.

Another multiple-maximum fabric presented in Figure $4 \mathrm{~d}$ (MDI) is difficult to explain because of the variation within the fabric. The pattern of MSC2 (Fig. 4e) suggests a fourmaxima fabric.

\section{Fabrics of fine ice}

The ice at the base of the ice cliffs was generally fine-grained. This ice has an average grain-size of 2 to $5 \mathrm{~mm}$, and it is equigranular with some dimensional orientation which defines the foliation plane and the flow direction. The bubble layers also give a significant indication of the foliation plane on which the linear arrangement of bubbles (lineation) is observable. The bubbles are generally ovoid and sometimes show long and thin columns in which the pressure ranges from i to 3 atmospheres. The maximum bubble pressure corresponds to the hydrostatic pressure of ice situated $30 \mathrm{~m}$ below the surface. Strain shadows within some grains are common.

A single-maximum fabric is characteristic of MSAI but the maximum is situated about ${ }_{1} 5^{\circ}$ from the pole of the foliation plane. It is on the line of the bubble lineation and is accompanied either by an incomplete or a complete great-circle girdle (Fig. $5 \mathrm{a}$ and b). The fabric of MSA2, at the same location, represents an emerging three-maxima type and indicates the apparent grain growth, though the actual crystal size remains in the range of fine-grained ice $(5.8$ grains per $\mathrm{cm}^{2}$ ) (Fig. 5c).

A pronounced single maximum centres on the pole of the foliation plane at MSBI (Fig. $5 \mathrm{~d}$ ). The density of concentration of $c$-axes is identical to that for the Thule area of Greenland, as discussed by Rigsby ( 1960 ). The sample from which Figure $5 \mathrm{~d}$ was obtained came from $30 \mathrm{~m}$ below the surface of the shear zone between the stagnant gully ice and the fast-moving ice stream. Its fabric corresponds to the single-maximum one of $\mathrm{MB}_{2}$ (Fig. ${ }_{3} \mathrm{f}$ ), which was collected at the surface. Weakening shear stress and grain growth at MSB2 might have produced the two-maxima pattern (Fig. 5e) at the western margin of the shear zone.

It is noticeable that there is a tendency to have two- or three-maxima fabrics associated with grain growth, even within a range of the fine-grained crystal sizes.

\section{Marble Rock fold}

A remarkable overturned fold structure was found in the ice cliff on the east of Marble Rock (Fig. 6). The structure is clearly shown by the moraine bands, which are essentially composed of fine sand, and the foliation plane is defined by the alternation of thin bubble-rich and bubble-poor layers. The obstruction by Marble Rock of the ice stream flowing towards the north has given rise to the recumbent fold and the upthrust structure. A belt of shear moraine is also observable in the cliff on its north-east end and this makes the fold structure more easily visible. At the western side of the area, a clear banded structure is made conspicuous by the alternation of bubble-rich and clear bands which are 0.5 to $5 \mathrm{~cm}$ thick. The

\section{Fig. 3 .}

a. IIO crystals of coarse ice $(M B I a)$ at grid B. Contours $I-3-5-7-9<\%$; maximum $17 \%$ per $I \%$ area.

b. 173 crystals of coarse ice $(M B I b)$ at grid $B$. Contours $1-2-3-5-7-9<\%$; maximum $12 \%$ per $1 \%$ area. The section is parallel to the adjacent layer.

c. 193 crystals of coarse ice (MCI) at grid C. Contours $1-3-5-7-9<\% ;$ maximum $10 \%$ per $1 \%$ area.

d. IOO crystals of coarse ice $(R M I)$; the surface ice of $10 \mathrm{~km}$ up-stream. Contours $1-3-5-7-9-1 \mathrm{I}-13<\%$; maximum $26 \%$ per $1 \%$ area.

e. $\quad I_{25}$ crystals of coarse ice $\left(\mathrm{MB}_{3}\right)$ east of grid B. Contours $I-3-5-7-9-1 I<\% ;$ maximum $20 \%$ per $I \%$ area.

$f$. 142 crystals of medium ice $(M B 2)$ at the shear zone between grids $A$ and $B$. Contours $I-3-4-5-7-9<\% ;$ maximum $9 \%$ per $1 \%$ area. 


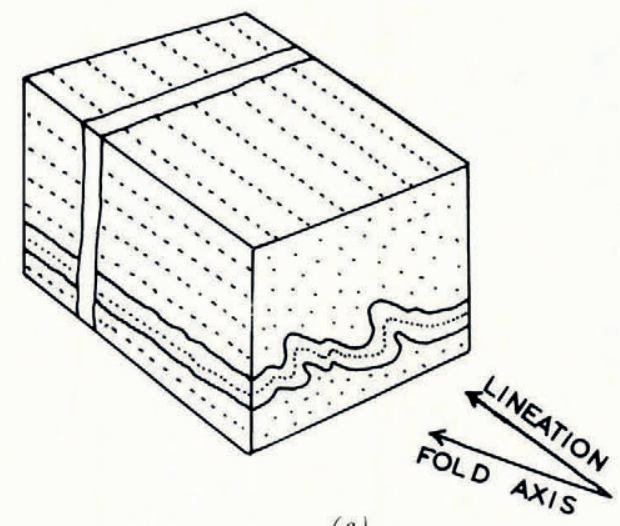

(a)

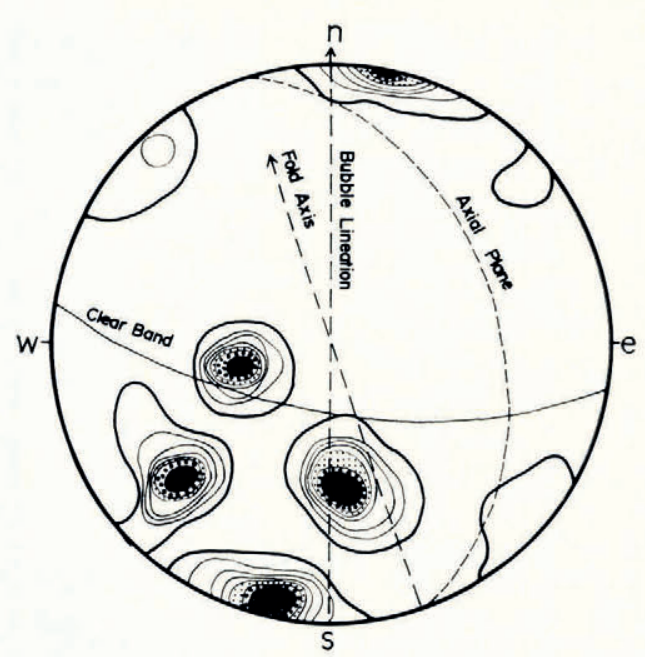

(b)

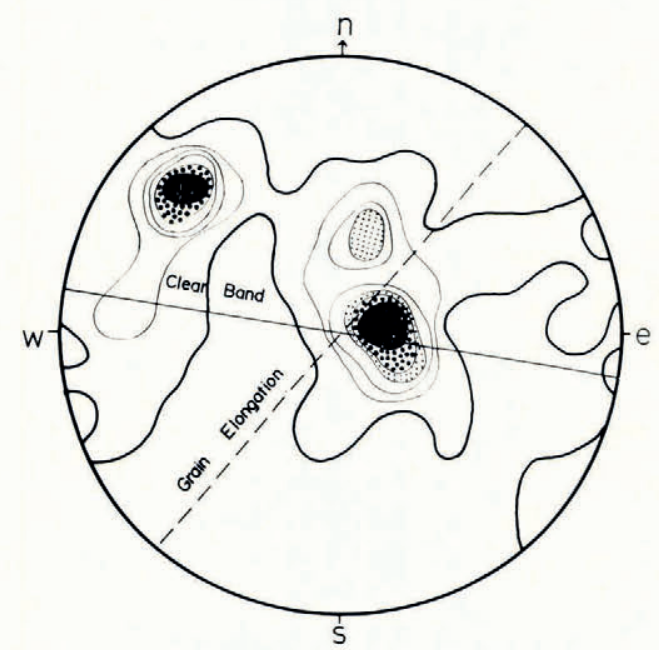

(c)

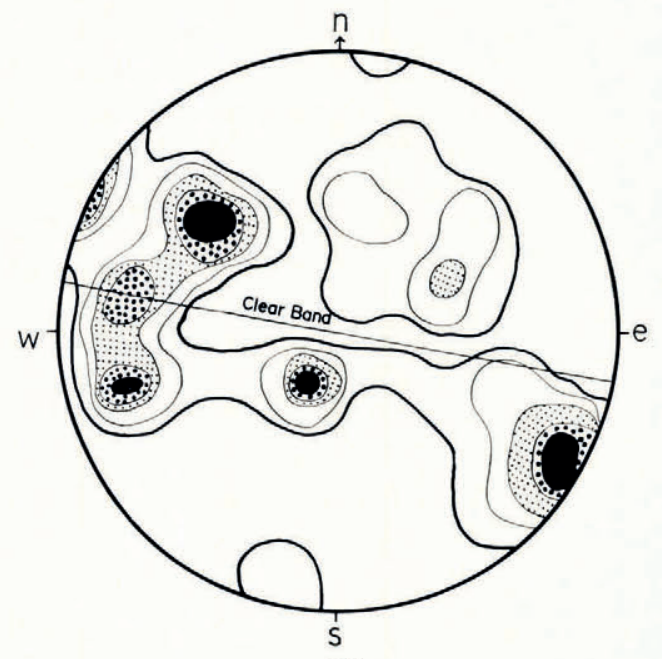

(d)

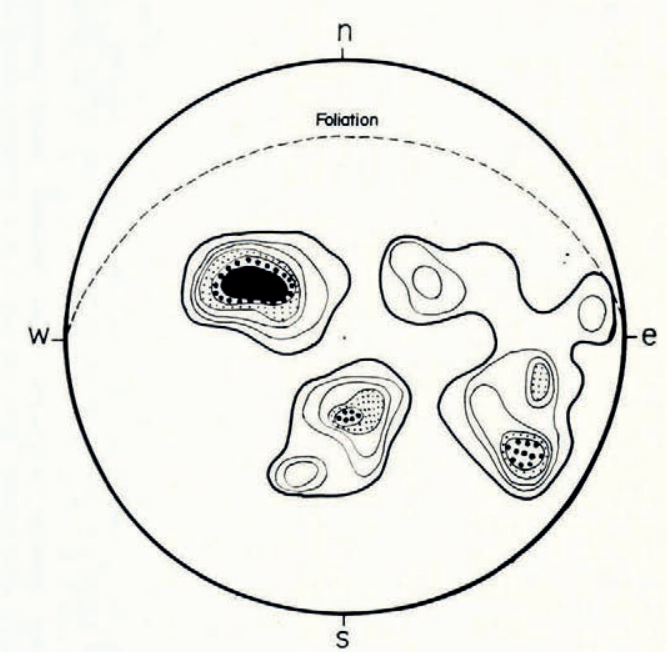

(e) 
bubble lineation in the banded structure indicates the glide direction. It is evident that all these structures must be the result of the upthrust movement of the ice stream onto Marble Rock. The crystals are consistently fine, flattened and elongated in texture, and the boundaries of the crystals are sometimes not clear; this is probably due to boundary flow in the sheared specimens. Intense strain shadows are common. The small bubbles ( 1 to $3 \mathrm{~mm}$ ) are ovoid and elongated, and they have pressures ranging from $I$ to 2 atmospheres.

The fabric pattern for the Marble Rock fold is basically a single-maximum fabric, although some girdles or sub-maxima are also present. It is evident that the single maximum is located on the pole of a shear plane which is called the axial plane of the fold, but not the pole of the foliation plane $\left(\mathrm{MSF}_{3}, \mathrm{MSF}_{4}, \mathrm{MSF}_{5}\right)$ inside the structure (Fig. $7 \mathrm{a}-\mathrm{c}$ ). The foliation plane, however, is still an effective controlling element on the fabrics of MSF2 and MSF6, which are outside of the fold. Both of these fabrics show high concentrations at the pole of foliation together with another maximum or sub-maximum on the pole of the shear plane which is nearly parallel to the axial plane. A similar observation has been made by Rigsby (r96o, p. 592); some of the diagrams from Malaspina Glacier were more closely related to the orientation of the foliation plane, which is parallel to the axial plane of the folds, than to the orientation of the limbs of the fold. The maxima of $\mathrm{MSF}_{4}$ and $\mathrm{MSF}_{5}$ are located on the line of the bubble lineation or elongation of the crystals about $15^{\circ}$ away from the pole of the plane. The former has an incomplete great-circle girdle, and the latter has a small girdle. These characteristics are quite similar to those of MSAI and MSA2, of which the latter could be a recrystallization fabric in the course of crystal growth.

The fabric of $\mathrm{MSF}_{3}$ also has a single maximum on the pole of the axial plane, but an associated girdle is composed of clear and coarser crystals $(0.8 \mathrm{~mm}$ as compared with $0.3 \mathrm{~mm}$ in groundmass) without strain shadows. It is clear that the orientation of the recrystallized coarser crystals may concentrate into a new sub-maximum, the controlling element of which is not known.

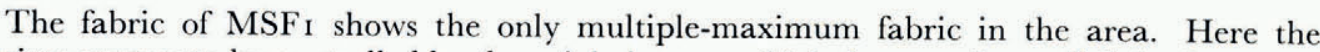
maxima appear to be controlled by the axial plane on which the crystals are slightly elongated, although the foliation plane is still significant; this can be seen by the alternation of bubble-rich and bubble-poor layers 2 to $6 \mathrm{~mm}$ thick (Fig. $7 \mathrm{f}$ ). It should be noted that this is the specimen with the largest grain-size among those collected in the area. The grain growth could cause a multiple-maximum fabric even under the moderate shear stress associated with the fold structure.

On the western side of the area, the orientation patterns of the banded ice are clear threemaxima fabrics (MSG I, Fig. 8a). The coarser grain-size ( 1.6 to 0.7 grains $/ \mathrm{cm}^{2}$ ) could be one of the reasons why these fabrics are different from those for the fold structure. MSG2a and MSG2b are the sections obtained from the bubble-free part with the coarser crystals and the bubbly part with the smaller crystals in the same specimen (Fig. $8 \mathrm{~b}$ and c). It is clear that a maximum at the pole of foliation of $\mathrm{MSG}_{2} \mathrm{~b}$ has moved out $16^{\circ}$ from the pole on the glide line and another maximum has appeared, thus making a multiple-maximum fabric of MSG2a in conjunction with grain growth.

Fig. 4 .

a. Block diagram of coarse ice $\left(M S D_{3}\right)$ showing a superimposed deformation. b. ${ }_{1} 45$ crystals of coarse ice $\left(\mathrm{MSD}_{3}\right)$ of Figure 4 . Contours ${ }_{1-3}-5-7-9-I I-I 3<\%$; maximum $21 \%$ per $1 \%$ area.
A superimposed fabrics.

c. ${ }_{1} 60$ crystals of fine ice $(M S C I)$. Contours $I-3-5-7-9-I I<\% ;$ maximum $12 \%$ per $I \%$ area.

d. ${ }_{5} 54$ crystals of coarse ice $\left(M D_{I}\right)$ west of grid C. Contours $1-2-4-6-8<\%$; maximum $10 \%$ per $1 \%$ area.

e. 62 crystals of coarse ice $(M S C 2)$. Contours $I_{-3}-5-7-9<\% ;$ maximum $17 \%$ per $1 \%$ area. 

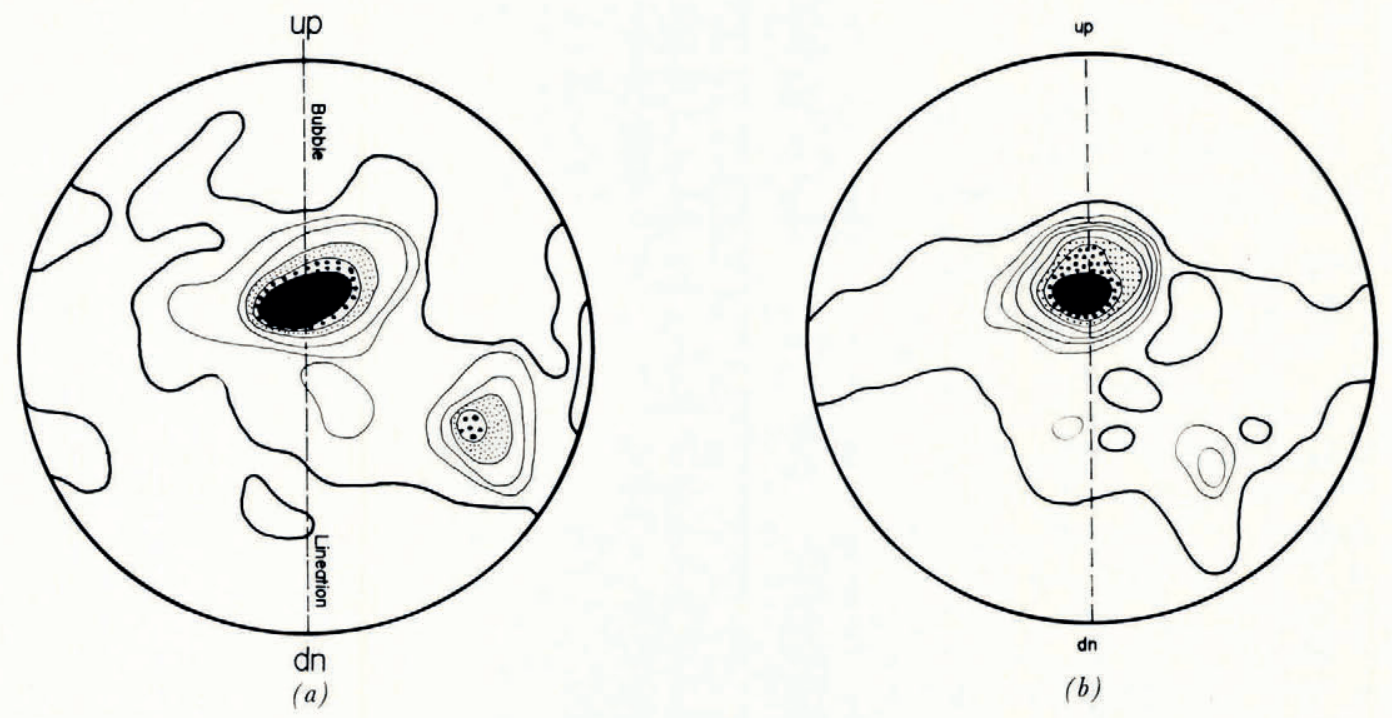

(b)

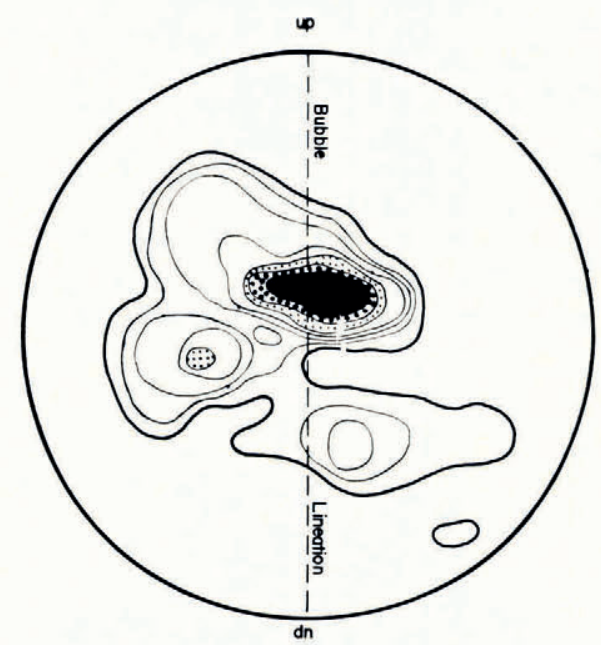

(c)
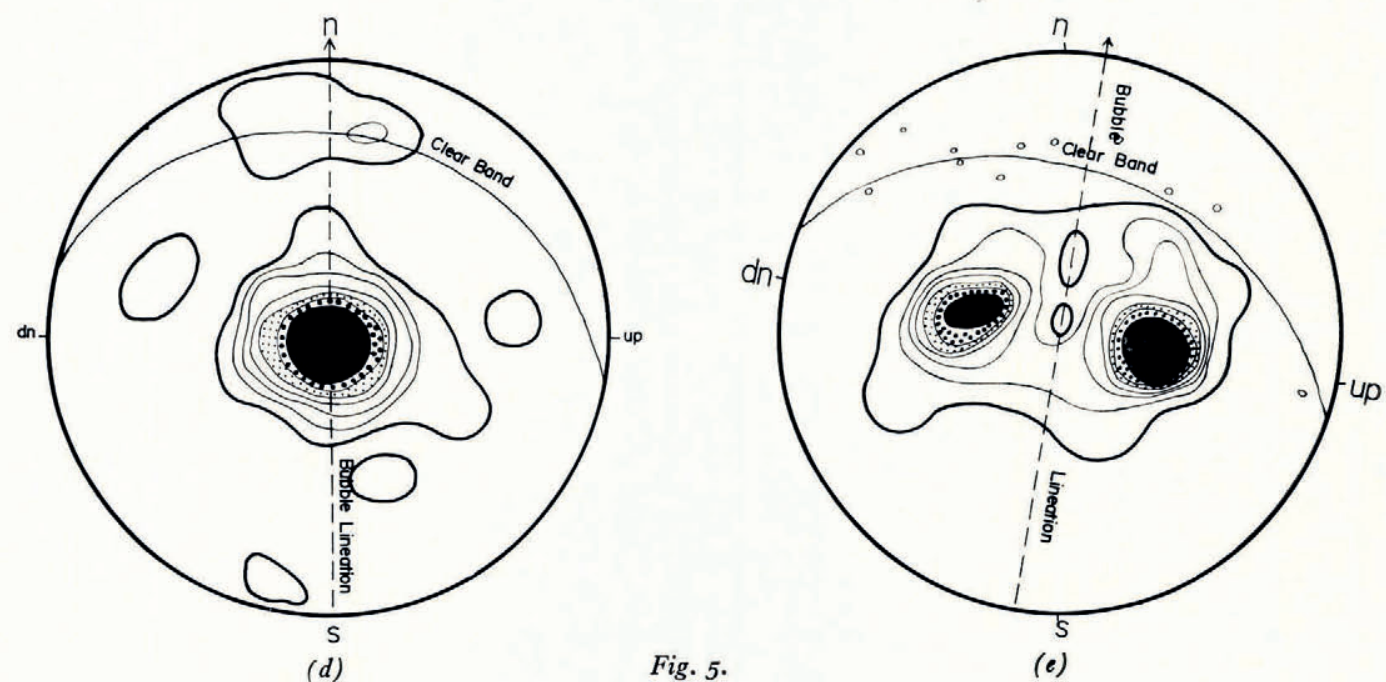

Fig. 5.

(e) 
Recrystallization* Fabrics

\section{Grain-growth effect}

It has been shown that the change of grain-size in ice has always given rise to a change in the fabric pattern at the same location or even in the same specimen. The tendency is consistently to have two or more and multiple-maxima fabrics arising from fabrics with a single maximum or a smaller number of maxima in the course of grain growth. This is particularly evident in the specimens of fine and medium grain-size. It has been noted that these fabrics are related to a controlling plane such as the foliation and axial planes except in newly formed ice.

The relation between grain-size, number of maxima and the distance of each maximum from the pole of the controlling plane is shown in Table V for selected specimens. Evidently, grain growth produces the increase in the number of maxima. Also, the single maximum at the pole of the controlling plane tends to shift away from the pole, resulting in two or more maxima; furthermore, the outward shift of each maximum of the three-maxima fabric from the centre is observable with an increase in the grain-size (MSG ${ }_{1}$ and 2, Fig. $5 \mathrm{~d}$ and e; MSG2a and b, Fig. 8b and c).

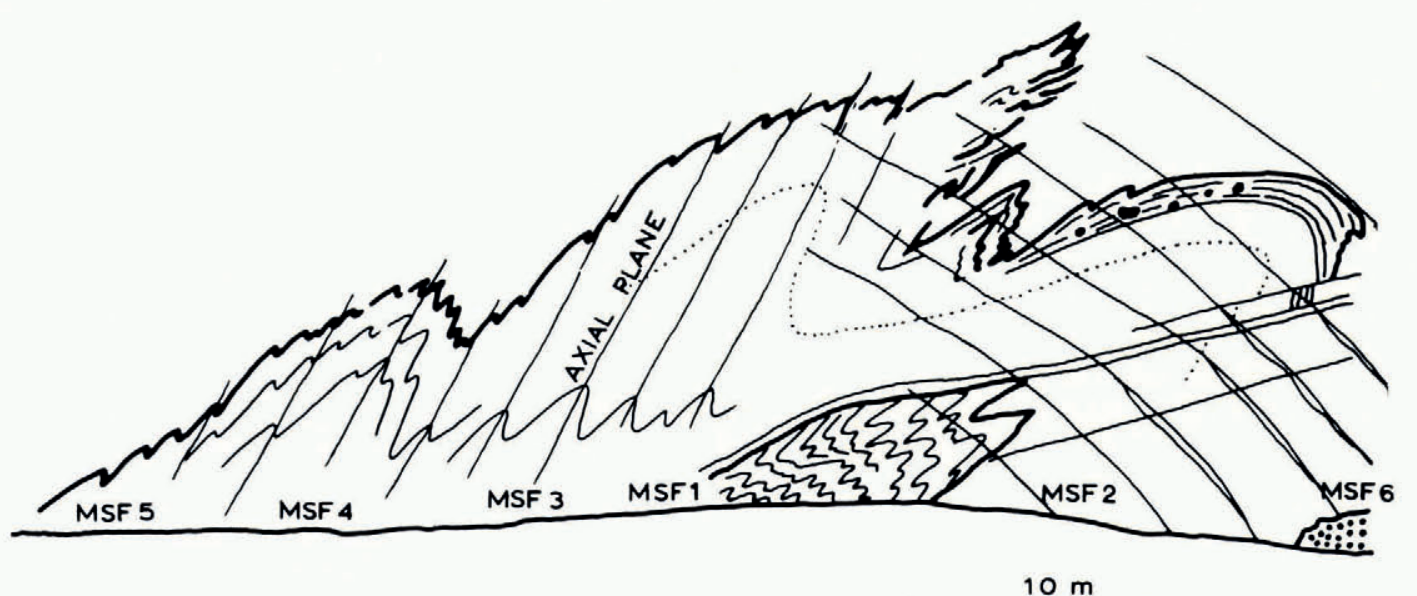

Fig. 6. Overturned fold structure at Marble Rock.

Kamb (1959) obtained single-maximum fabrics from fine ice layers and multiplemaximum fabrics from coarse layers, each of which alternated closely with the other, so that he inferred the multiple-maximum fabric was a recrystallization fabric. Rigsby (196o, p. 605) has also stated that recrystallization under melting conditions probably tends to change the strong orientation of crystals from a single maximum with optic axes normal to the foliation plane into three or four maxima.

* Recrystallization here signifies essentially secondary recrystallization in the strict sense.

Fig. 5 .

a. 130 crystals of fine ice (MSAIa). Contours $1-3-5-7-9-1 I<\% ;$ maximum $15 \%$ per $1 \%$ area.

b. I5o crystals of fine ice $(M S A I b)$, which is a clear band in MSAIa. Contours $1-3-5-7-9-1 I<\% ;$ maximum $15 \%$ per $1 \%$ area.

c. 232 crystals of fine ice $(M S A 2)$. Contours $1-2-4-6-8-I O-I 2<\%$; maximum $18 \%$ per $1 \%$ area.

d. I 140 crystals of fine ice $(M S B I)$. Contours $I-3-5-7-9-I I-I 3<\% ;$ maximum $34 \%$ per $I \%$ area.

e. $\quad I 20$ crystals of medium ice $(M S B 2)$. Contours $I-3-5-7-9-1 I-13<\%$; maximum $27 \%$ per $1 \%$ area. Open circles indicate the bigger crystals from the clear band. 


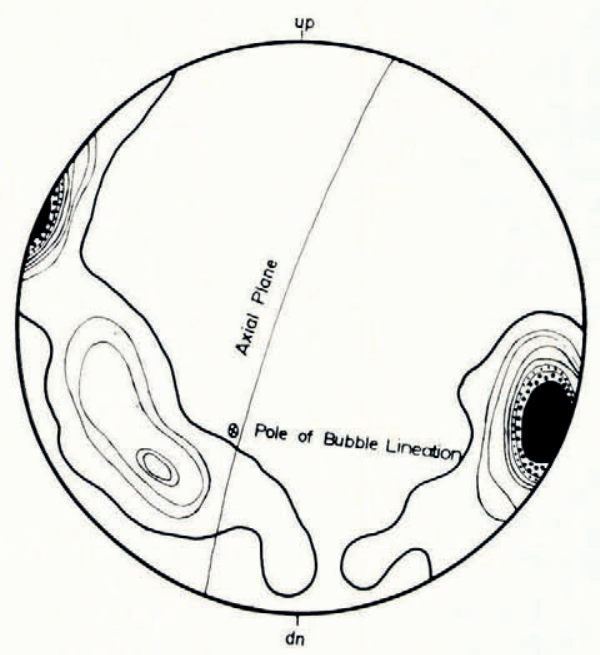

(a)

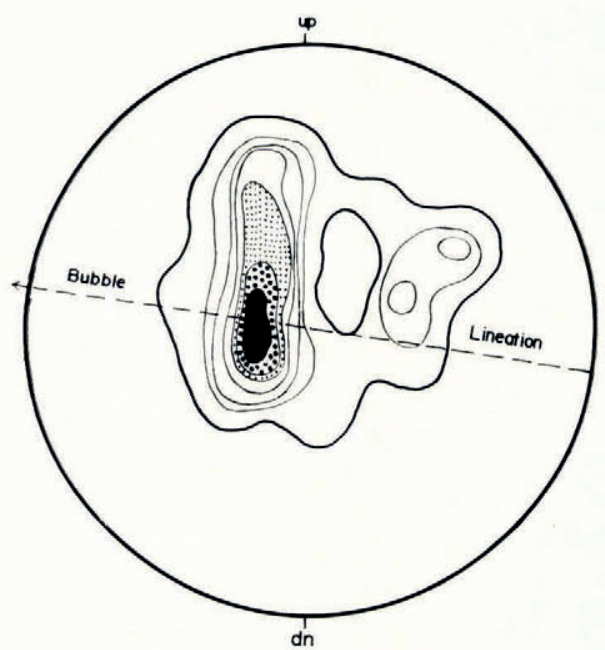

(c)

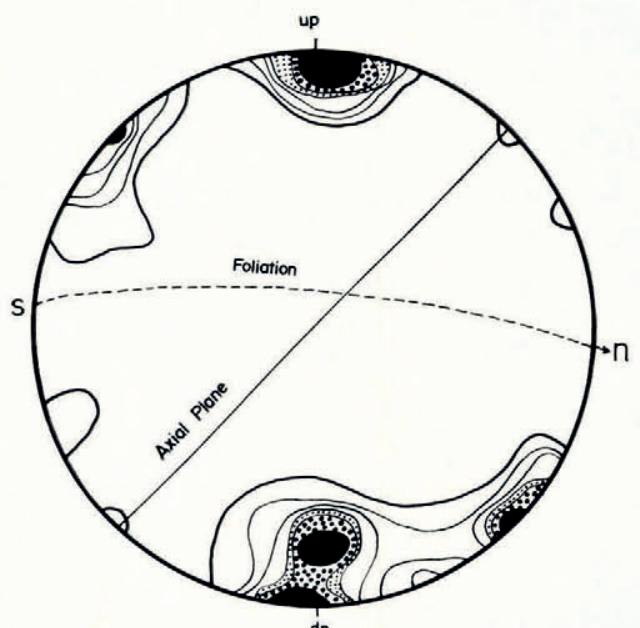

(e)

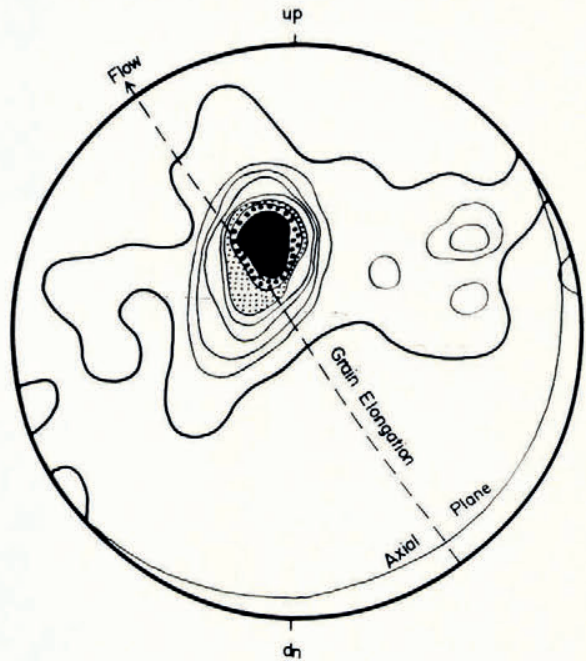

(b)

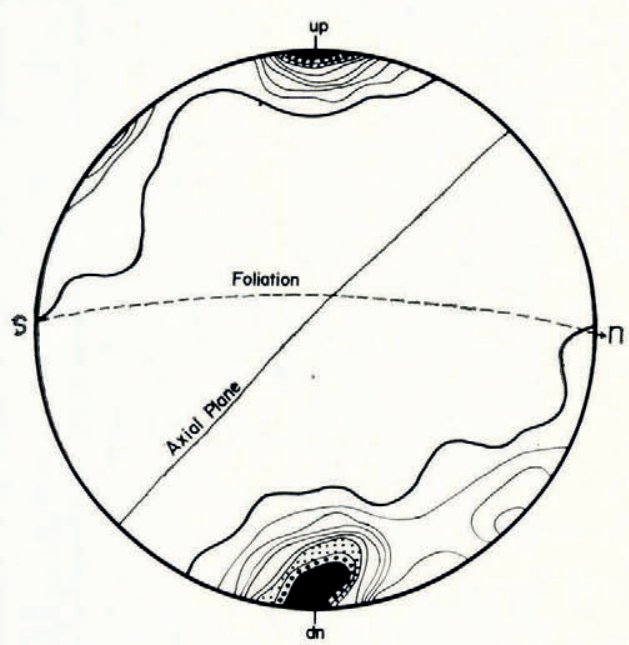

(d)

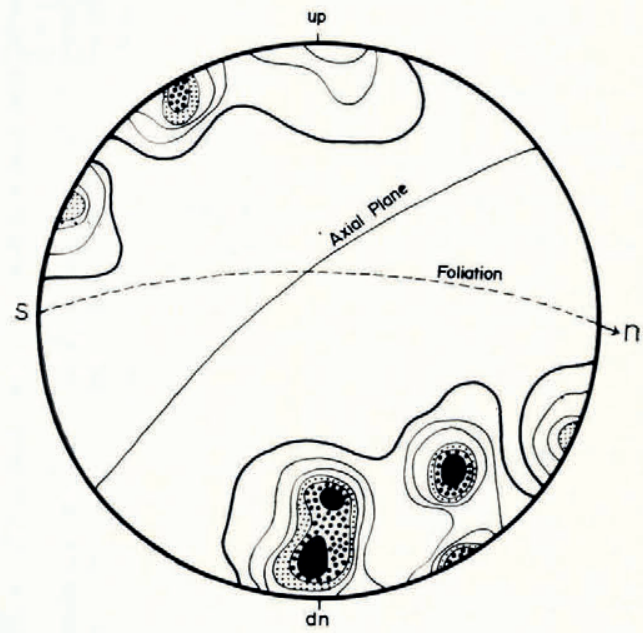

(f) 
Table V. Grain-size, Number of Maxima and Distance from the Pole of Controlling Plane

\begin{tabular}{|c|c|c|c|}
\hline & $\begin{array}{c}\text { Grain-size } \\
\left(\text { number } / \mathrm{cm}^{2}\right)\end{array}$ & Number of maxima & $\begin{array}{l}\text { Distance from pole of } \\
\text { controlling plane }\end{array}$ \\
\hline $\mathrm{MSF}_{3}$ & I 5.0 & 1.o & $0^{\circ}$ \\
\hline MSA $_{I}$ & 13.5 & 1.5 & $16^{\circ}, 43^{\circ}$ \\
\hline $\mathrm{MSB}_{\mathbf{I}}$ & 12.5 & 1.0 & $0^{\circ}$ \\
\hline $\mathrm{MSF}_{4}$ & 9.0 & I.0 & $16^{\circ}$ \\
\hline MSA2 & 5.8 & 2.5 & $14^{\circ}, 30^{\circ}, 32^{\circ}$ \\
\hline $\mathrm{MSB}_{2}$ & 4.0 & 2.0 & $30^{\circ}, 30^{\circ}$ \\
\hline $\mathrm{MSF}_{5}$ & $3 \cdot 3$ & I. 5 & $15^{\circ}$ \\
\hline $\mathrm{MSG}_{2} \mathrm{~b}$ & 1.6 & 3.0 & $0^{\circ}, 30^{\circ}, 45^{\circ}$ \\
\hline $\mathrm{MSF}_{\mathrm{I}}$ & 1.2 & $4 \cdot 5$ & $16^{\circ}, 24^{\circ}, 25^{\circ}, 31^{\circ}, 4^{2}$ \\
\hline MSG2a & 0.7 & $4 \cdot 5$ & $16^{\circ}, 17^{\circ}, 22^{\circ}, 3^{\circ}, 5^{\circ}$ \\
\hline
\end{tabular}

As is clearly shown above, even in the fine grain-size range, the evidence indicates that the coarser the grain-size, the greater the number of maxima formed and the further the maxima move away from the pole of the foliation plane, although there may be a limit to the distance moved. The relation between the grain-size and the number of maxima, and between the grain-size and the distance from the pole of the controlling plane is plotted in Figure ga and b. These figures confirm the influence of recrystallization, particularly annealing crystallization, on the orientation pattern of crystal axes of ice under non-hydrostatic stress conditions.

The distance of each maximum of a multiple-maxima fabric, mainly the four-maxima fabric, from the pole of the controlling plane varies greatly among the figures of many investigations so far (Reid, r 964 , p. 258). This has probably been due to the variability in grainsize, i.e. the grade of recrystallization.

A frequency diagram for the distance of each maxima from the pole of the controlling plane in the area investigated reveals some tendencies towards concentration on $0^{\circ}, 17^{\circ}, 23^{\circ}$ and $30^{\circ}$ (Fig. IO). One of them, $0^{\circ}$, is the only position of a maximum which has been verified experimentally as well as theoretically as the basal glide. As for the other angles, they could reflect the influence of the symmetry of the crystal lattice of ice. However, neither the crystallographic treatment nor the thermodynamic prediction so far seems to explain satisfactorily the positions of these maxima as a stable fabric.

Annealing is essentially a de-orientating process, as shown by Rigsby's (1960) experiment. What could happen under syntectonic crystallization, i.e. annealing plus deformation, is likely to provide the multiple-maxima fabrics with or without a small girdle in general centred on the pole of foliation.

In the course of grain growth of ice both from the bottom of the ice cliffs and the surface of the ice stream, particularly near the surface where grain growth is conspicuous from the summer temperature gradient, the pattern of the orientation fabric generally changes from a single-maximum one to a multiple-maxima one, typically a three-maxima fabric when stability is reached.

\section{Axis-distribution analysis}

If grain growth were the only cause of the change in orientation of ice optic axes, the coarser crystals could have different orientations from the smaller ones in the same thin section. This is one of the reasons why Kamb (1959) employed scatter diagrams with different symbols for different crystal sizes. This difference between the large and small grains is observable in

\section{Fig. 7.}

a. $\quad I 70$ crystals of fine ice $\left(M \mathrm{MF}_{3}\right)$. Contours $I_{-3}-5^{-7}-9-1 I_{-1}-15<\%$; maximum $27 \%$ per $I_{0} \%$ area.

b. 180 crystals of fine ice $\left(M S F_{4}\right)$. Contours $1-3-5-7-9-11-13-15<\%$; maximum $26 \%$ per $1 \%$ area.

c. $\quad I 70$ crystals of medium ice $\left(M S F_{5}\right)$. Contours $1-3-5-7-9-1 I-13<\%$; maximum $18 \%$ per $1 \%$ area.

d. 220 crystals of fine ice $\left(M S F_{2}\right)$. Contours $I-3-5-7-9-I I-I 3-I 5-I 7<\% ;$ maximum $24 \%$ per $I \%$ area.

e. 210 crystals of fine ice $(M S F 6)$. Contours $1-3-5-7-9-1 I<\%$; maximum $17 \%$ per $1 \%$ area.

f. I 140 crystals of medium ice $\left(M S F_{I}\right)$. Contours $I-3-5-7-9-I I<\%$; maximum $14 \%$ per $1 \%$ area. 
the fabric of $\mathrm{MSF}_{3}$ (Figs. $7 \mathrm{a}$ and $\mathrm{I} \mathrm{Ia}$ ) in which the axes of fine grains ( 2 to $4 \mathrm{~mm}$ ) concentrate on the pole of the axial plane of the fold, whereas those of the coarser crystals $(8 \mathrm{~mm})$ and the crystals of the clear band tend to cluster near the pole of the lineation of the bubbles, and also form a girdle. There is hardly any spatial differentiation between them except for the clear band. The recrystallization orientation might take place in association with clear-band formation because the orientation of the coarser crystals is identical to that of crystals in the clear band.

Axis-distribution analyses were carried out on some sections. These were to determine whether there was any relationship between the orientation groups of the crystals and their positions in the thin section. If such a relationship could be found to exist, then it might be

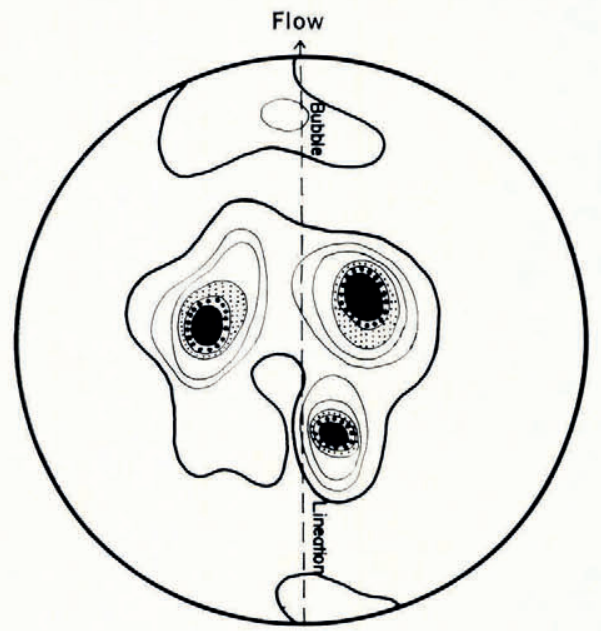

(a)

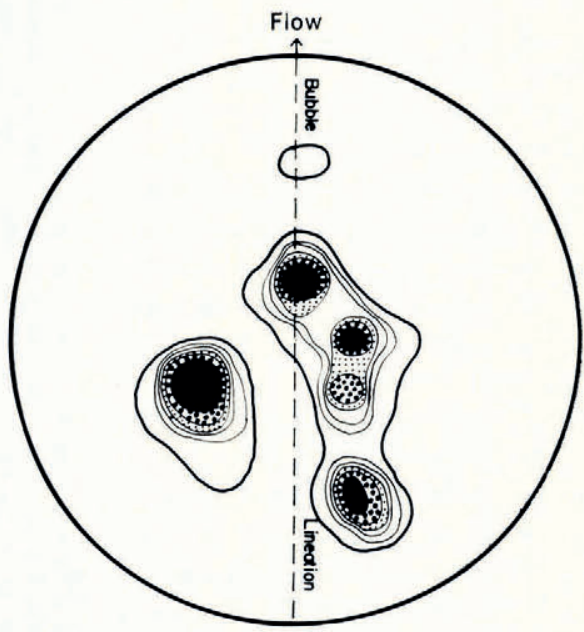

(b)

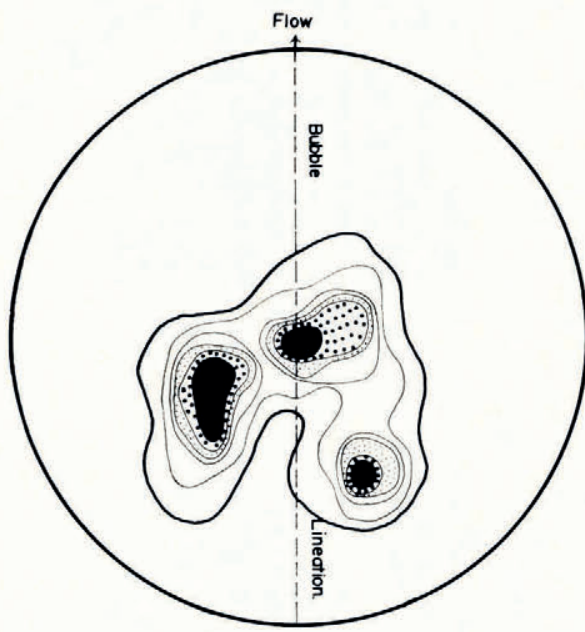

(c)

Fig. 8.

a. $I^{2}$ crystals of medium ice $\left(M S G_{I}\right)$. Contours $I-3-5-7-9-I I<\%$; maximum $20 \%$ per $I \%$ area.

b. $\quad 1$ oo crystals of coarse ice (MSG $2 a)$. Contours $I-3-5-7-9-1 I<\%$; maximum $26 \%$ per $I \%$ area. Bubble-free part of banded ice.

c. $\quad 160$ crystals of medium ice $(M S G 2 b)$. Contours $1-3-5-7-9-I I<\%$; maximum $20 \%$ per $I_{1}^{\circ}$ area. Bubbly part of banded ice. 
possible to associate the fabric with a deformation domain such as the region of shear bands in a thin section. The deformation domain actually exists as a row of grains, of which each individual shows the same orientation in a fine-grained and a sheared sample. However, the samples with crystals large enough for the axis-distribution analyses do not show any deformation domain or spatial distribution of the orientation of $c$-axes in the thin sections (Fig. I Ib and c). It may therefore be suggested that such a domain which existed in fine and sheared specimens, could be obliterated during the process of recrystallization.

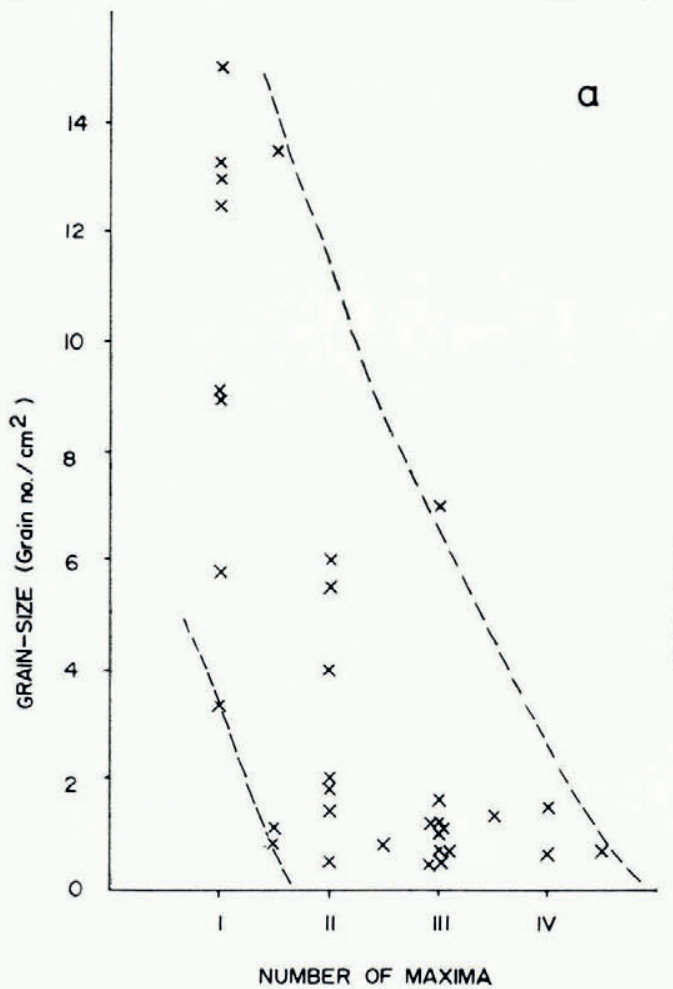

Fig. 9 .

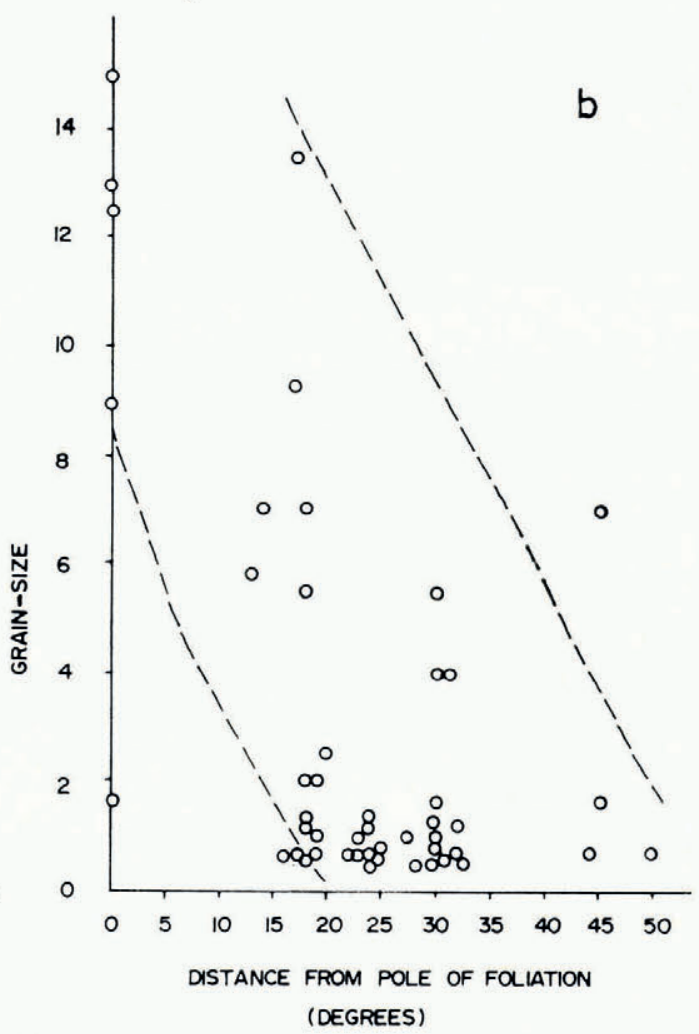

(DEGREES)

a. Relation of grain-size (grain number $/ \mathrm{cm}^{2}$ ) to number of maxima.

b. Relation of grain-size to distance from pole of foliation.

\section{Strain and Fabric Pattern}

The principal strain axes calculated from the strain-grid measurements in this region are marked on each diagram and the relation between the strain-rates and the fabric patterns are examined with reference to the predictions by Brace (I96o). It is anticipated that his predictions could somehow be adapted to the grid A area, because the ice there might not be much affected by recrystallization after new ice is formed. Even so, only one fabric of the four diagrams, viz. the one which is more intensely deformed than the others, can be roughly adapted to Brace's case I. The other three fabrics cannot be fitted to it at all. In other words, even in a grid with $100 \mathrm{~m}$ diagonals, the orientation fabric is always changing due to recrystallization even though it may have little effect in this case. It seems reasonable that the direct effect of stress and strain on the orientation fabric of ice may be much smaller in recrystallized ice, especially the coarser ice, although the stress field is necessary to a certain extent to produce such patterns as three and four maxima. 
The only pure deformation phenomenon observed in ice crystals in thin sections is the formation of strain shadows resulting from crystal bending. Strain shadows were found in almost all specimens from this region, but the number of crystals showing them in a thin section was quite small. The orientation of the crystals showing strain shadows was found to be no different in general from that of the other crystals. Strain shadows represent undulatory extinction bands parallel to the optic axis, and narrow wavy bands with the same orientation are generally alternately arranged to indicate a periodic bending of the basal pinacoid of the ice crystal. The angle of bending is $5^{\circ}$ on the average but it can reach $16^{\circ}$. It has sometimes been observed that the sharp boundaries between the parts with different orientations happen to show polygonization under maximum bending. The maximum bending angle obtained in natural ice of this region is in agreement with the figure $\left(\right.$ less than $\left.15^{\circ}\right)$ found by experimental deformation of an ice plate (Wakahama, ig64).

That bending is associated with basal slip has been clearly illustrated by Nakaya (I958) on single crystals and by Wakahama (1964) on polycrystalline ice. Furthermore, bending causes the $c$-axes to rotate.

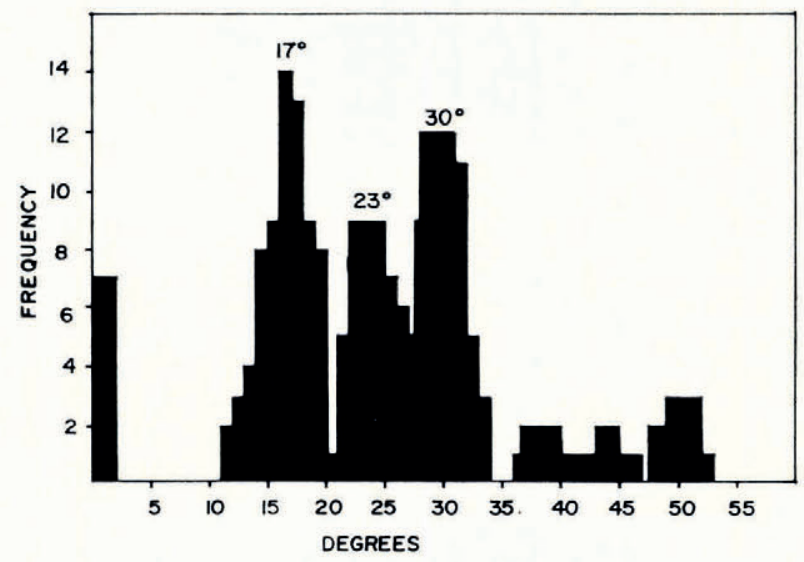

Fig. Io. Frequency diagram of distances of maximum from pole of controlling plane; 63 maxima.

An example of the rotation of the $c$-axes of strained crystals in the thin section of $\mathrm{MB}_{3}$ is shown together with the directions of the maximum compression axis, maximum tensile axis and maximum shear directions in Figure 12. It seems that the plot of the $c$-axes of bent crystals tends to move parallel to either the direction of the maximum compression axis or in some cases the direction of the maximum tensile axis, but in others the direction of maximum shear. Although the $c$-axes should theoretically tend to rotate such as to approach the direction of the maximum compression, this does not seem to happen in the present case.

\section{Concluding Remarks}

The ice crystals in a glacier are continually being subjected to gliding, bending and recrystallization under the action of glacier flow. The deformation mechanism of ice is considered to be consistent with that of rocks or metals, so that it can be accounted for by factors such as translation gliding, Riecke's diffusion and grain-boundary flow. Strain shadows are presumably due to intra-crystalline translation gliding. Riecke's diffusion is a phase change in crystals related to stress vectors, i.e. it is a recrystallization phenomenon. Grain-boundary 
flow can be clearly observed in those specimens with fine grains which have been subjected to intense deformation. These factors govern the preferred orientation of ice crystals which are associated with a stress field in glaciers.

It is, however, evident that syntectonic-secondary recrystallization, i.e. crystal growth with stress, is effective in producing orientation fabrics with two, three and multiple maxima. Also the maxima always shift away from the pole of foliation as the grain-size increases, but it appears that there are several stable positions for maxima as shown in Figure io. This figure

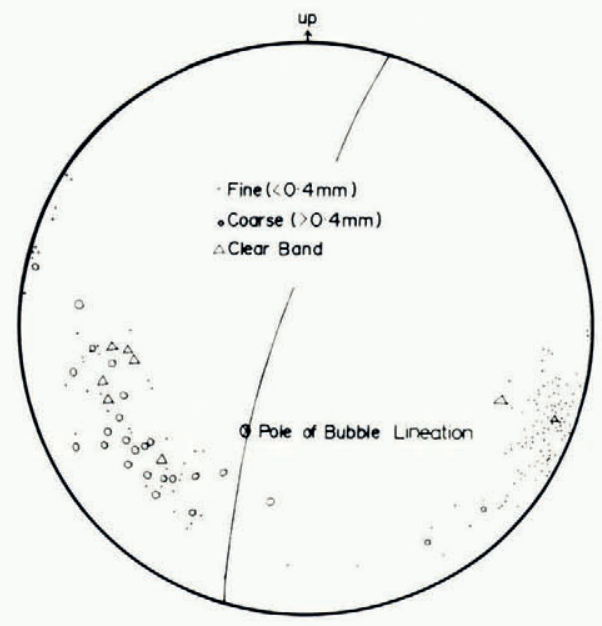

(a)

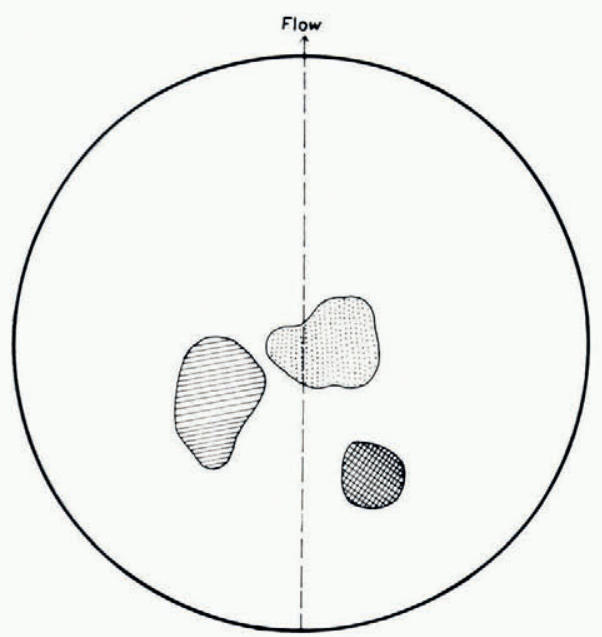

(b)

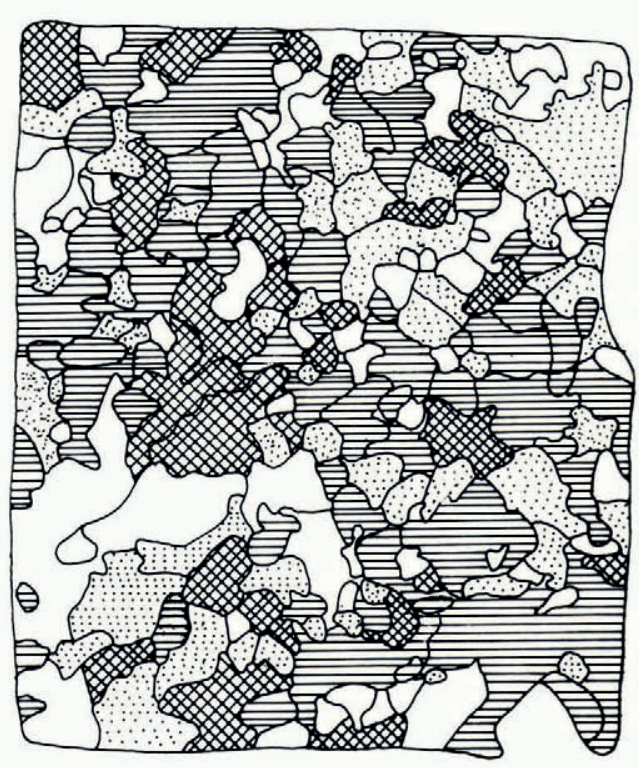

(c)

Fig. $I I$.

a. Scatter diagram of $\mathrm{MSF}_{3}$, of which a contoured diagram is shown in Figure 7 a. Recrystallized crystals and crystals of the clear band tend to have a different orientation from that of the original fine crystals.

$b$ and $c$. Axis-distribution of MSG2b, of which a contoured diagram is shown in Figure $8 c$. No spatial relationship is seen for groups with different orientations. 
suggests that there are three significant angles between a maximum and the pole of foliation other than $0^{\circ}$, viz. $17^{\circ}, 23^{\circ}$ and $30^{\circ}$. Furthermore, it may be expected that more stable angles would occur with coarser crystals as has been typically found in temperate glaciers. These stable angles could reflect the symmetry of the crystal lattice of ice, although it is necessary to verify this theoretically as well as experimentally.

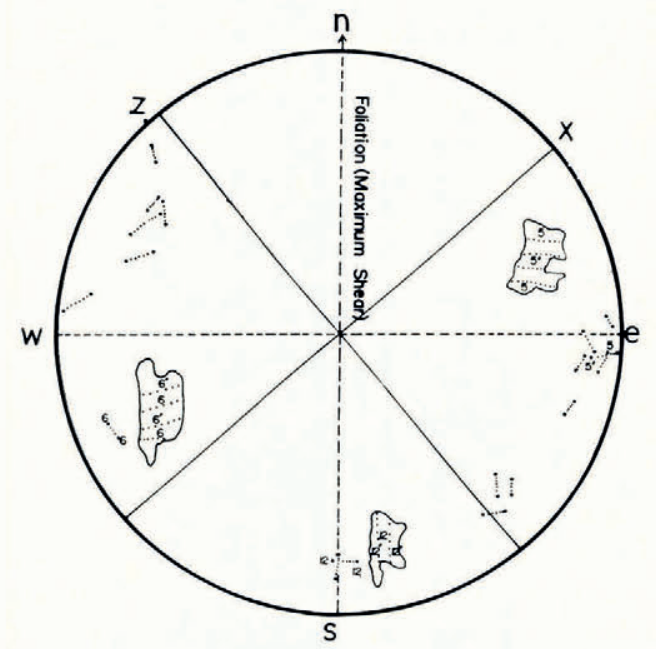

Fig. I2. The shift of optic axes in strained crystals. Note the periodic bending.

\section{ACKNOWLedgements}

The author gratefully acknowledges the help and support by all the members of ANARE at Mawson station in 1966. Mr W. Budd, of the Antarctic Division, helped in the preparation of the programme, provided the results of his own work, made many valuable suggestions and also reviewed this manuscript. Dr U. Radok, of the Department of Meteorology, University of Melbourne, advised on the programme and critically reviewed the manuscript. The author wishes to express his deep gratitude to them. This paper is published with permission of the Director of the Australian Antarctic Division.

MS. received 6 February 1968 


\section{REFERENCES}

Bader, H. 1951. Introduction to ice petrofabrics. Journal of Geology, Vol. 59, No. 6, p. 519-36.

Brace, W. F. 1960. Orientation of anisotropic minerals in a stress field. Memoirs. Geological Society of America, No. 79, p. 9-20.

Budd, W. 1967. Ablation from an Antarctic ice surface. (In Oura, H., ed. Physics of snow and ice: international conference on low temperature science. ... 1966. ... Proceedings, Vol. 1, Pt. 1. [Sapporo], Institute of Low Temperature Science, Hokkaido University, p. $43 \mathrm{I}-46$.)

Fairbairn, H. W., and Chayes, F. 1949. Structural petrology of deformed rocks. Cambridge, Mass., Addison-Wesley Press.

Kamb, W. B. 1959. Ice petrofabric observations from Blue Glacier, Washington, in relation to theory and experiment. Fournal of Geophysical Research, Vol. 64, No. 1 1, p. $1891-1909$.

Langway, C. C., jr. 1958. Ice fabrics and the universal stage. U.S. Snow, Ice and Permafrost Research Establishment. Technical Report 62.

Meier, M. F. 1960. Mode of flow of Saskatchewan Glacier, Alberta, Canada. U.S. Geological Survey. Professional Paper $35 \mathrm{I}$.

Mellor, M. 1959. Ice flow in Antarctica. Journal of Glaciology, Vol. 3, No. 25, p. 377-85.

Nakaya, U. 1958. The deformation of single crystals of ice. Union Géodésique et Géophysique Internationale. Association Internationale d'Hydrologie Scientifique. Symposium de Chamonix, I6-24 sept. 1958, p. 229-40.

Nye, J. F. 1959. A method of determining the strain-rate tensor at the surface of a glacier. Fournal of Glaciology, Vol. 3, No. 25, p. 409-19.

Reid, J. R. 1964. Structural glaciology of an ice layer in a firn fold, Antarctica. (In Mellor, M., ed. Antarctic snow and ice studies. Washington, D.C., American Geophysical Union, p. 237-66. (Antarctic Research Series, Vol. 2.))

Rigsby, G. P. 1951. Crystal fabric studies on Emmons Glacier, Mount Rainier, Washington. Fournal of Geology, Vol. 59 , No. 6 , p. $590-98$.

Rigsby, G. P. 1960. Crystal orientation in glacier and in experimentally deformed ice. Fournal of Glaciology, Vol. 3, No. 27, p. 589-6o6.

Scholander, P. F., and Nutt, D. C. 1960. Bubble pressure in Greenland icebergs. Fournal of Glaciology, Vol. 3, No. 28 , p. $671-78$.

Shumskiy, P. A. 1958. The mechanism of ice straining and its recrystallization. Union Géodésique et Géophysique Internationale. Association Internationale d'Hydrologie Scientifique. Symposium de Chamonix, I6-24 sept. 1958, p. $244-48$.

Steinemann, S. 1958. Experimentalle Untersuchungen zur Plastizität von Eis. Beiträge zur Geologie der Schweiz. Geotechnische Serie. Hydrologie, Nr. Io.

Taylor, L. D. 1963. Structure and fabric on the Burroughs Glacier, south-east Alaska. Fournal of Glaciology, Vol. 4 , No. 36 , p. $731-52$.

Wakahama, G. I964. Kōri no sosei henkei ni tsuite. V. Takesshōhyō no sosei henkei [On the plastic deformation of ice. V. Plastic deformation of polycrystalline ice]. Teion-kagaku: Low Temperature Science, Ser. A, [No.] 22, p. $1-24$.

Ward, W. H. 1955. Studies in glacier physics on the Penny Ice Cap, Baffin Island, 1953. Part IV. The flow of Highway Glacier. Journal of Glaciology, Vol. 2, No. 18, p. 592-99.

Wu, T. H., and Christensen, R. W. 1964. Measurement of surface strain-rate on Taku Glacier, Alaska. Fournal of Glaciology, Vol. 5, No. 39, p. 305-13.

\section{APPENDIX}

Four specimens were obtained at the tongue of Forbes Glacier about $20 \mathrm{~km}$ west of Mawson station. The pattern of orientation of the $c$-axes is quite typically that of a three-maxima fabric at and near the surface of the glacier $\left(\mathrm{FG}_{3}\right.$ and $\mathrm{FG}$ ia; Fig. $13 \mathrm{a}$ and $\left.\mathrm{b}\right)$. Also, grain growth from the bottom towards the surface gives rise to an outward shift of maxima from the pole of foliation from FGia $\left(18^{\circ}, 24^{\circ}, 30^{\circ}\right)$ to $\mathrm{FG}_{3}\left(25^{\circ}, 30^{\circ}, 30^{\circ}\right)$.

The specimen $\left(\mathrm{FG}_{2}\right)$ from io $\mathrm{m}$ below the surface is fine in grain-size with elongated bubble lineation parallel to the flow direction. Its fabric with two maxima and a girdle represents a complex superimposed pattern (Fig. I3d).

The fabric of FGrb, a specimen which was collected from a clear lens $10 \mathrm{~cm}$ thick and $100 \mathrm{~cm}$ long in the bubbly ice of FGia $5 \mathrm{~m}$ below the surface, is surprisingly consistent with the pattern of Steinemann's (1958, p. 46-5o) torsion-shear experiment, immediately after unloading (Fig. I3c). Very fine crystals (less than 1 mm) aggregate to form an irregular lens and they are distributed along the grain boundaries of coarser crystals which closely resemble a sheared quartzite or a sort of mylonite. Furthermore, all of the bubbles are segregated out to the boundaries of the grains. The texture of the ice is obviously different from ordinary glacier ice. It is clear that the ice must have been subjected to intense shearing deformation in order to reduce the grain-size and to segregate the bubbles. According to the direction of these lenses of very fine crystals, the new orientation of the shearing deformation seems to have been normal to the flow direction. Thus, the rotation of the flow direction could have produced a fabric identical to that of the torsion-shear experiment by Steinemann, though the original positions of the maxima of FGia still seem to have remained effective in the new sheared fabric of FGib. 


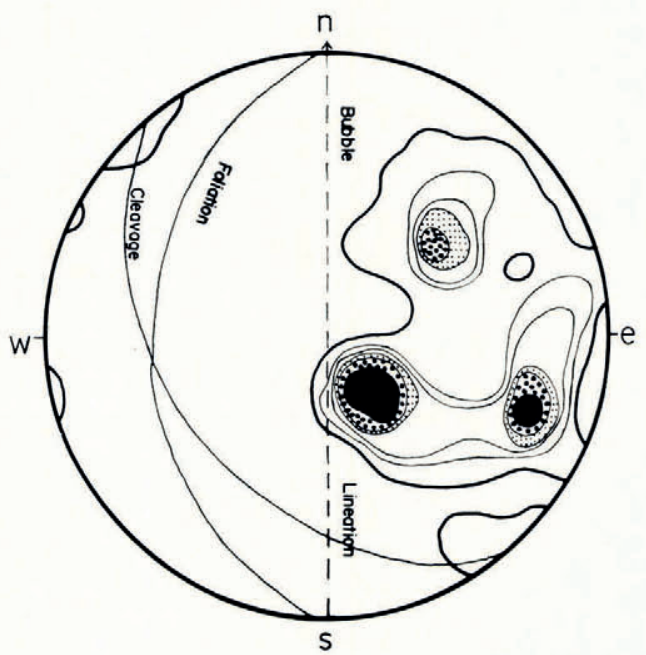

(a)

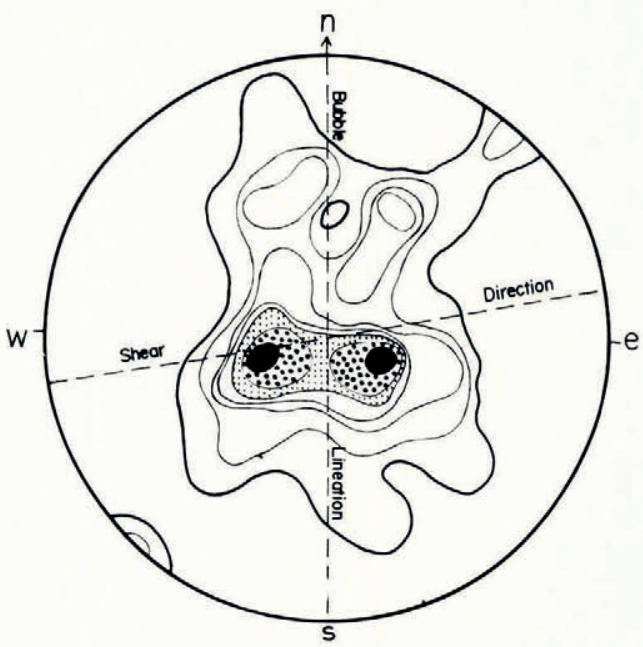

(c)

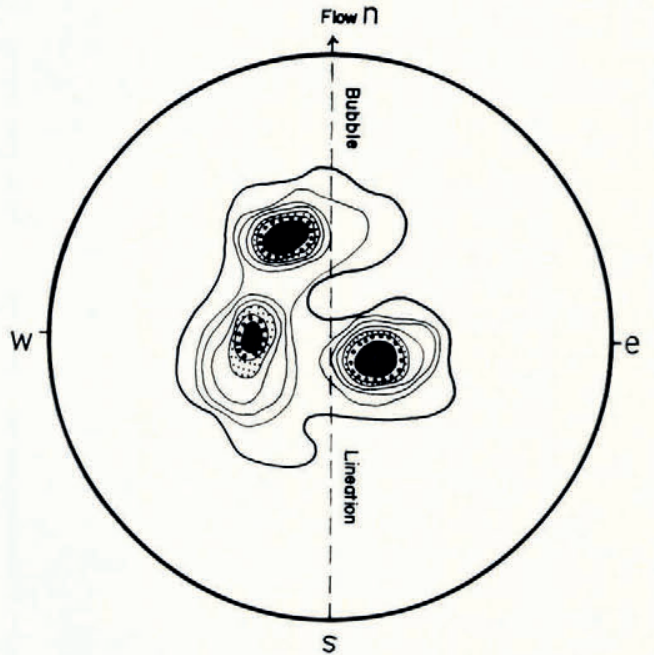

(b)

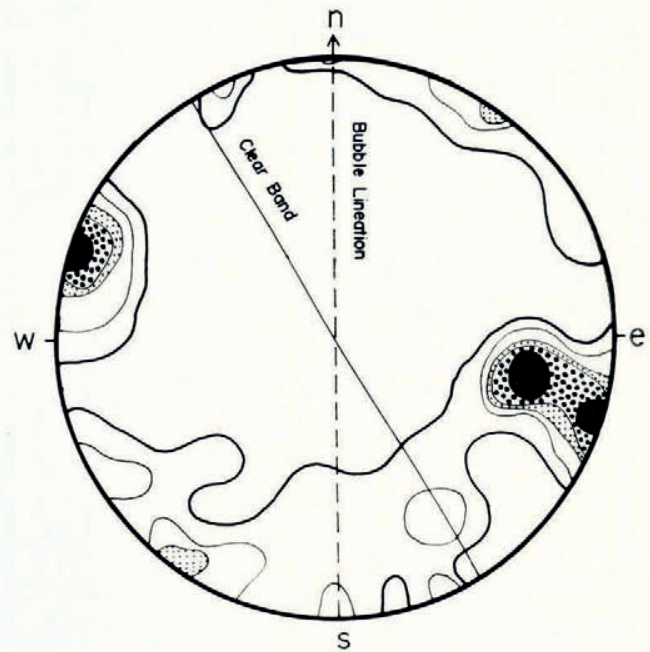

(d)

Fig. I3.

a. $I 70$ crystals of coarse ice $\left(F G_{3}\right)$ from Forbes Glacier. Contours $I-3-5-7-9-I I<\% ;$ maximum $20 \%$ per $I^{\circ} \%$ area. Surface sample.

b. I 40 crystals of medium ice (FGIa) from Forbes Glacier. Contours $I-3-5-7-9-I I-I 3<\%$; maximum $20 \%$ per $1 \%$ area. $5 \mathrm{~m}$ below surface.

c. 220 crystals of medium ice $(F G I b)$ from Forbes Glacier. Contours $I-2-3-4-5-7-9<\% ;$ maximum $I O^{\circ} \%$ per $I \%$ area $5 \mathrm{~m}$ below surface. Clear lens from FGIa.

d. 260 crystals of fine ice $(F G 2)$ from Forbes Glacier. Contours $1-3-5-7-9<\%$; maximum $15 \%$ per $1 \%$ area. $10 \mathrm{~m}$ below surface. 